\title{
Mortality Rate and Property Rights in a Model with Human Capital and R\&D*
}

\author{
Tiago Neves Sequeira ${ }^{\dagger}$
}

\begin{abstract}
We use a set of established growth models, which simultaneously include human capital and R\&D, to show that the effect of mortality rate in human capital accumulation is quantitatively more important than the effect of perfectly guaranteed patents on research. First, we show that the effect of mortality rate on human capital accumulation productivity may explain differences in growth paths and development levels across countries, accounting for the main features of economic development of the industrialized world in the last two centuries. Then, we explicitly compare the two types of expropriation (mortality rate and uncertainty in property rights).
\end{abstract}

JEL Classification: O10, O11, O17, P14.

Key-Words: Institutions, Incentives, Economic Growth, Economic Development, Industrial Revolutions.

\section{Introduction}

Different paths of growth have led to very different levels of GDP per capita even among developed countries. This has recently been attributed to differences in institutions between countries. We follow the suggestion of Douglas North (1994), who, in his Nobel Lecture, refers to economic growth theory arguing that "when applied to economic history and development it focused on technological development and more recently human capital investment but ignored the incentive structure embodied in institutions that determine the extent of societal investment in those factors". He emphasized that "the speed

\footnotetext{
*I am grateful to Ana Balcão Reis, José Tavares, António Antunes and Luciano Amaral for their helpful insights on this paper and to John Huffstot for text revision. I gratefully aknowledge Holger Strulik for the supply of Matlab codes for Funke and Strulik (2000). I also gratefully aknowledge finantial support from the Fundação Amélia de Melo. The usual disclamer applies.

${ }^{\dagger}$ Faculdade de Economia, Universidade Nova de Lisboa, and Departamento de Gestão e Economia, Universidade da Beira Interior.
} 
of economic change is a function of the rate of learning, but the direction of that change is a function of the expected payoffs to acquiring different kinds of knowledge".

This paper analyzes the effect of different types of incentives in a standard model with physical capital, human capital and R\&D. In particular, the economy evolves from a neoclassical physical capital model to a Lucas human capital model and finally to an R\&D model, as in Funke and Strulik (2000). We are interested in a comparison between human capital and R\&D enhancing institutions. For that, we compare the influence of the sensivity of human capital to mortality rate (or of mortality rate itself) with the influence of property rights on ideas on growth and development. We think these are the most important "incentives" studied in the literature for each of the most well-known engines of growth (human capital and R\&D).

First, we mimic the recent evolution of the developed world, following the industrial revolution, being particularly concerned with the transitions between stages of economic growth, in which agents face incentives to invest in different assets, evaluating the importance of the mortality rate effect on human capital accumulation and growth.

Then, we want to compare the effect of mortality rate (through human capital) with the effect of property rights (through $\mathrm{R} \& \mathrm{D}$ ) on economic growth and development. These have been the most cited types of expropriation to explain different growth paths. For example, Jones (2001), argued that the existence of protected patents for $\mathrm{R} \& \mathrm{D}$ was the single most important factor in driving an industrial revolution. On the influence of Mortality Rate, there are three cited channels through which it affects human capital accumulation:

- a decrease in the mortality rate and the simultaneous decrease in fertility tend to increase parental investment in each child - the parental investment channel - (Zhang et al. 2001, 2003 and Kalemli-Ozcan et al., 2000);

- mortality rate is correlated with the health status of the population: a decrease in mortality induces increases in the human capital quality and thus accumulation of human capital becomes more productive; this is related to the Cost of Illness approach - the health channel - (Bloom, Canning and Sevilla, 2001 and Croper, 2000, p.336);

- high mortality rate reduces expected value of future returns from education - the returns channel - (Meltzer, 1992 and Preston, 1980, cited in Kalemli-Ozcan et al., 2000). Preston (1980) reported a small effect.

We do not study reverse causality between human capital accumulation and the decline of mortality rate nor its effect on aggregate savings. ${ }^{1}$

\footnotetext{
${ }^{1}$ According to Zhang et al. (2003), there are two opposite effects on savings: lower mortality tends to increase savings because people want to smooth consumption throughout more periods and it reduces savings because lower longevity reduces accidental bequests. These authors argue that the first effect dominates in poor countries and the latter in the rich countries.
} 
There is some historical evidence for the USA, supported by Haines (2001), who pointed out that the sustained mortality transition only began about the 1870s. The author also argues that thereafter the decline of urban mortality proceeded faster than in rural places, assisted by significant public works improvements and advances in public health and eventually medical science. The negative correlation between current mortality rate and future economic growth can be seen in the following figures for several countries. The last panel shows the correlation between school enrollment and life expectancy in the USA.
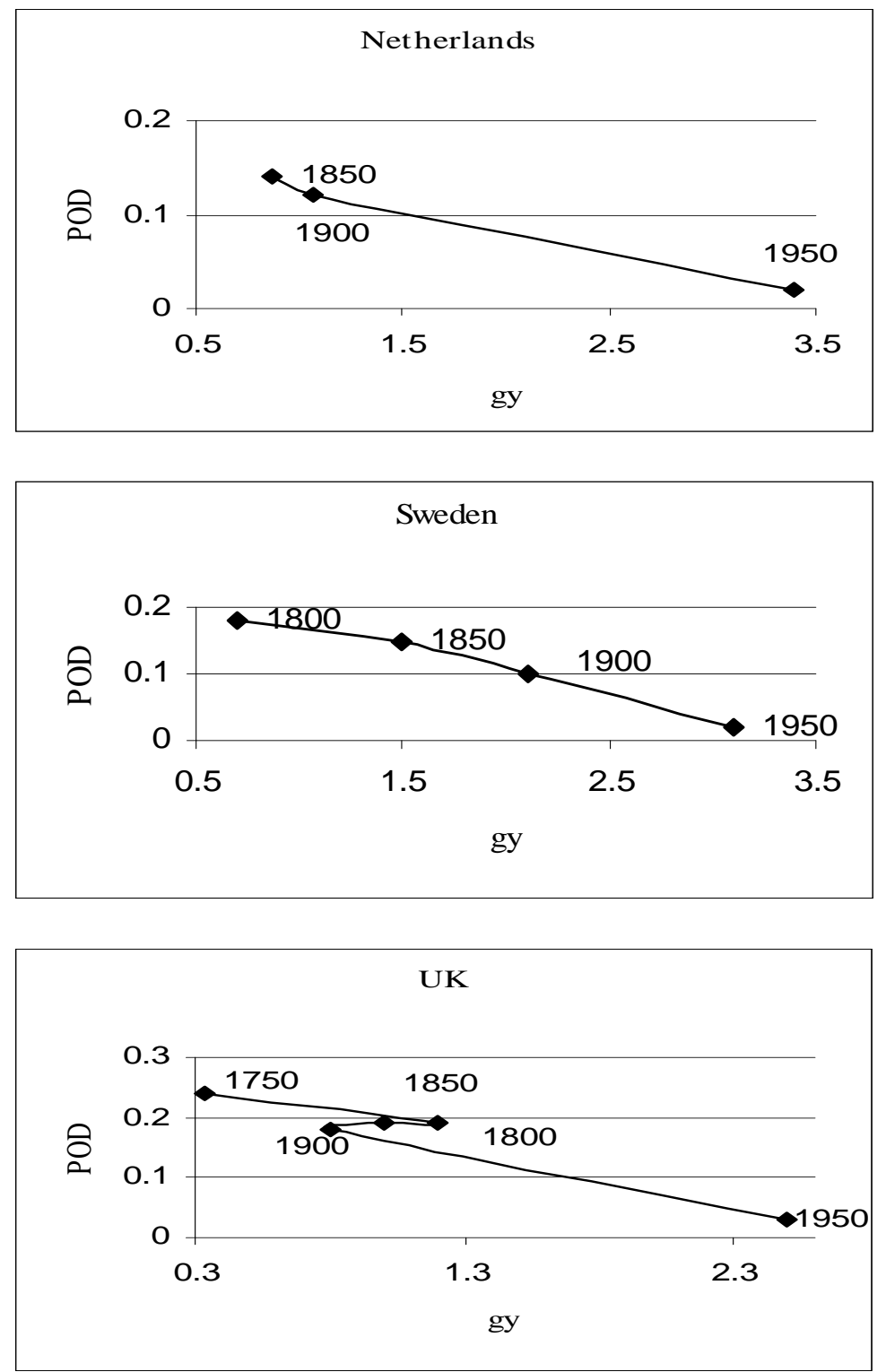

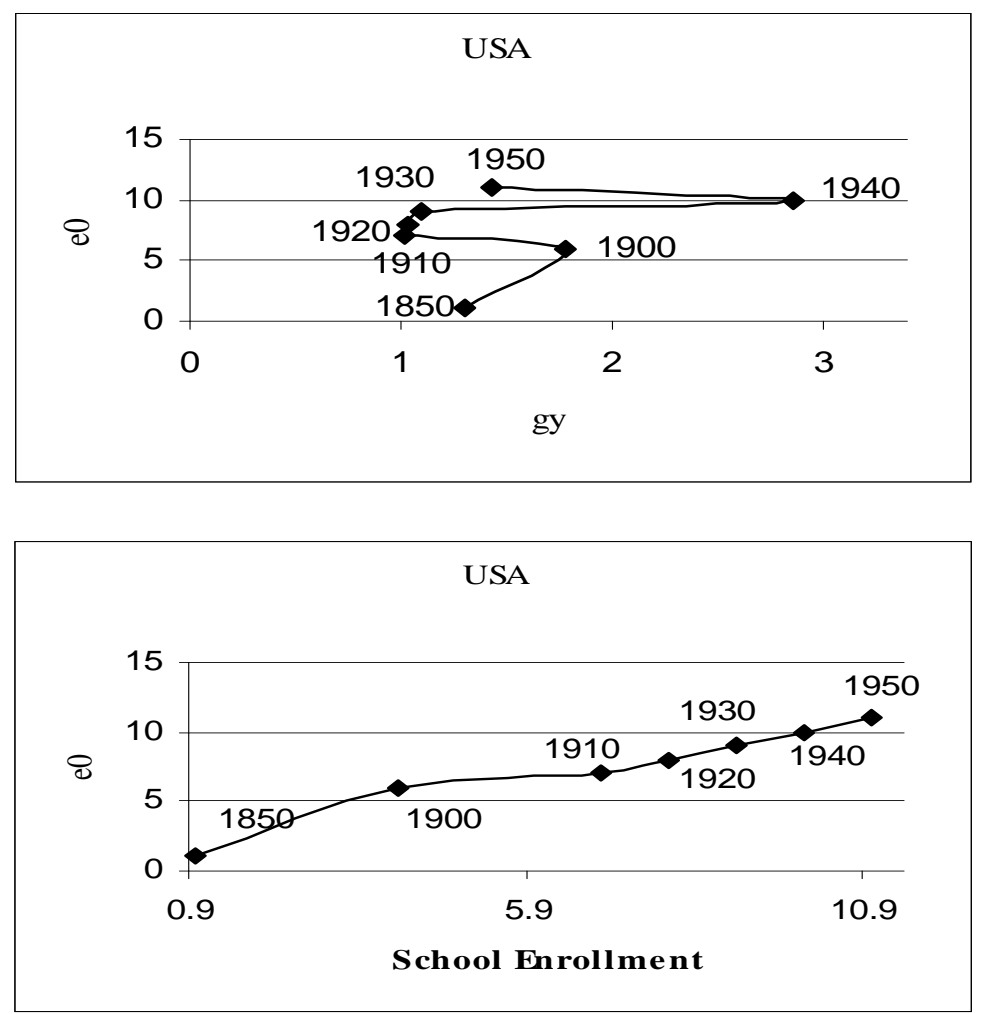

Figure 1. Correlations between Mortality, Human Capital and Economic Growth

Definitions: $\mathrm{e}_{0}$ is Life Expectancy at birth, POD is Probability of Dying before 1 year old and $g_{y}$ is per capita growth rate of GDP. Economic Growth for Netherlands, Sweden and United Kingdom are for the periods 1700-1820 (which corresponds to

1750 in the figure), 1820-1870 (1800), 1870-1913 (1850), 1913-1950 (1900) and $1950-1973$ (1950). For the USA, life expectancy is in the indicated year and economic growth rate is in the following period (e.g. 1910 and 1910-1920).

Sources: Kalemli-Ozcan (2002) for POD, Maddison (1995 and 2001) for growth rates and Costa and Steckel (1995) for $\mathrm{e}_{0}$ and School Enrollments (these last two variables were constructed as ranks by year).

Mortality has also been used as an empirical instrument for current institutions and explains a large part of existing productivity differences between countries (Acemoglu et al., 2001). This author argues that low mortality rates showed by settlers in colonies influence the creation of protective institutions to the accumulation of different types of capital and potentially to R\&D.

There is an established effect of the mortality decline in economic growth through human capital accumulation: this will be an assumption in our model, which will be quantitatively evaluated. 
As we focus on the quantitative properties of the model, the treatment of institutions in this paper is simple and of reduced-form, as for instance, in Jones (2001).

To sum up, this paper adds to the literature the simultaneous study of the impact of two different types of expropriation mechanisms on quite standard endogenous growth models with transition mechanisms (as in Funke and Strulik, 2000) between them. It also simulates modern times with the model, showing that the effect of the mortality rate on human capital accumulation productivity is important to mimic the main features of the development process of the last two centuries. It also attempts to evaluate the role of the State in building in the incentives structure. This is important concerning the recent discovery that "state antiquity" contributes significantly to the explanation of differences in growth rates and is a good instrument for institutional quality, as Bockstette et al. (2002) had argued.

In Section 2, we present the benchmark model. In Section 3, we describe the different stages and analyze the influence of mortality rate and property rights on ideas in the transitory steady-states. In Section 4, we present a comparison between predictions from the model and from economic history. In section 5 , we describe the model dynamics. In Section 6 , we explicitly compare the two types of expropriation. Then, in Section 7, we evaluate the role of Government as tax collector to improve or enforce institutions. Finally, we conclude in Section 8.

\section{The model}

The Model builds on Funke and Strulik (2000) and adds two main features: (1) demographic settings and (2) property rights. ${ }^{2}$

\subsection{Engines of Growth and Institutions}

Institutions are understood as society features that protect engines of growth from being expropriated. The features studied here are mortality rate, as an expropriation mechanism of human capital and erosion of property rights over new ideas, as an expropriation mechanism over R\&D.

Individuals may spend part of their human capital, $H_{H}$, on development of skills. This non-market activity is described by a production function of the Uzawa (1965) - Lucas (1988) type, which is extended to include the idea that the mortality rate decreases the productivity of human capital production:

$$
\dot{H}=(\xi-\gamma d) H_{H}
$$

with productivity parameter $\xi>0$, the mortality rate $d$ and the sensitivity of human capital accumulation to the mortality rate $\gamma$. The mortality rate is

\footnotetext{
${ }^{2}$ In different extensions, we introduced a tax over assets and spillovers. Main differences are presented in appendix. Results are presented in Sections 4.3 to 6
} 
introduced in a way that directly reduces human capital productivity. ${ }^{3}$ This assumption links the effect of the mortality rate with human capital accumulation through its health and parental investment channels. ${ }^{4}$ The effect of malnutrition or chronic disease, such as asthma or bronchitis, on the children's productivity in schools are quite appealing examples. Thus the sensitivity $\gamma$ may be correlated with other incentives to accumulate human capital (other than mortality but related with it) in the economy, say, public investment on educational infrastructure as primary schools or medication spread, which lower morbidity. As formal education becomes cheaper, individuals may become less responsive to the mortality rate. As medication evolves and becomes more widespread, diseases become less effective in decreasing human capital accumulation, as they cause a decrease in the inabilities related to chronic diseases. Note that $\gamma=0$ imply that mortality rate does not influence the accumulation of human capital, which means that institutions such as schooling and health care can be so good that the level of mortality does not imply lower productivity in accumulating skills.

A growth accounting approach to this function suggests that human capital is determined by the quantity of human capital, $H_{H}$, by productivity $\xi$, and by the quality of human capital, $-\gamma d$. Jorgenson and Fraumeni (1993) show that productivity influence on educational output growth is quite low in the period between 1948 and 1986 in the USA, but labor quantity and quality have a greater influence. In an exploratory analysis, Bloom, Canning and Sevilla (2001) show that accounting for productivity differences across countries, life expectancy has a significantly positive effect on GDP per capita growth and decreases the significance and influence of schooling and experience. According to these authors, work experience is insufficient to account for cross-countries development differences. Although these do not constitute definite evidence to support the belief that these factors are more important than productivity strictu sensu, there is sufficient evidence to argue that these factors are crucial. Thus, we suggest that the parameter $\xi$ (strictu sensu productivity of human capital in the education sector) is not particularly different between countries and throughout time.

With this parameterization, changes in mortality given the sensitivity, or in the sensitivity given the mortality have exactly the same effect. We will use only the sensitivity, given that we want to study the influence of institutions and mortality can be given by historical data. Below, we will show equivalence between this approach and others that evaluate the impact of the mortality rate.

\footnotetext{
${ }^{3}$ Another possible way to introduce mortality is $\dot{H}=\xi H_{H}-\gamma d H$, which also guarantees the existence of steady state. It can be shown that this possibility implies exactly the same growth rate of human capital as the adopted one, changing only the share of human capital in the education sector.

${ }^{4}$ Its relationship with parental investment is better seen calculating the effort in human capital accumulation $u_{H}$ (given below after Table 1), which depends negatively on $\gamma$ and $d$. Although there are a few other ways to think of an impact of mortality on human capital through the returns channel (see, for instance Kalemli-Ozcan et al. (2000)), our parameter $\gamma$ also works through wages, in a way that is explained below.
} 
Production of a new intermediate good requires the invention of a new blueprint. For emphasis of the following exposure, we assume that output of new ideas is determined solely by the aggregate knowledge employed in the R\&D-sector and excludes spillovers or duplication effects that were present, for instance, in Jones (1995). We will discuss below the effects of a setting with spillovers. The production function of new ideas is made according to:

$$
\dot{n}=\epsilon H_{n}
$$

with efficiency parameter $\epsilon>0$ and human capital affected to R\&D activities, $H_{n}$.

To consider property rights, we want to introduce uncertainty about whether the value of patents will be guaranteed forever. A tractable way to model the gradual erosion of monopoly power (suggested in Barro and Sala-i-Martin (1995), p.223) is to assume that goods transform from monopolized to competitive with a probability that is generated from a Poisson process. ${ }^{5}$ Thus, if a good is invented at time $\mathrm{t}$ and is initially monopolized, the probability of it still being monopolized at the future date $\tau$ is $\mathrm{e}^{-p(\tau-t)}$, in which $p d T$ is the probability that the good becomes competitive in the next interval $d T$. Let $v_{t}$ denote the expected value of innovation, defined by

$$
v_{t}=\int_{t}^{\infty} e^{-[R(\tau)-R(t)+p(\tau-t)]} \pi(\tau) d \tau, \text { where } R(\tau)=\int_{0}^{t} r(\tau) d \tau
$$

An economy without property rights laws and enforcement rules corresponds to setting $p$ equal to $+\infty$. In this case the economy cannot enter into an $\mathrm{R} \& \mathrm{D}$ stage simply because monopoly is never guaranteed, and it will never be. Thus, there are no profits to compensate for $\mathrm{R} \& \mathrm{D}$ costs. Taking into account the cost of innovation as implied by (2), free entry conditions in $R \& D$ are defined as follows:

$$
\begin{gathered}
w / \epsilon=v \text { and } H_{n}>0, \dot{n}>0 \text { or } \\
w / \epsilon>v \text { and } H_{n}=0, \dot{n}=0
\end{gathered}
$$

Finally, no-arbitrage requires that the valorization of the patent plus profits less the probability of erosion of monopoly power is equal to investing resources in the riskless asset:

$$
\dot{v}+\pi-p v=r v \Leftrightarrow \frac{\dot{v}}{v}=r+p-\pi / v
$$

\footnotetext{
${ }^{5}$ This is exogenous (as in Jones (2001)). This erosion of monopoly power is also a way to study time-limited patents, using a certainty equivalence approach: say that a monetary unit applied in an uncertain patent has to yield the same returns as the same amount applied in a time-limited patent. Thus $\int_{0}^{\infty} e^{-(r+p) t} d t=\int_{0}^{T} e^{-r t} d t$.
} 


\subsection{Other technologies and market structure}

The output of the final good depends on the physical capital $(K)$, human capital affected to final good production $\left(H_{Y}\right)$ and differentiated goods $(D)$ using a Cobb-Douglas technology:

$$
Y=A_{1} K^{\beta} D^{\eta} H_{Y}^{1-\beta-\eta} \beta, \eta>0, \beta+\eta<1
$$

The index of intermediates is represented by the usual Dixit and Stiglitz formulation:

$$
D=\left[\int_{0}^{n} x_{i}^{\alpha} d i\right]^{1 / \alpha}
$$

where $n$ denotes the number of available varieties and $x_{i}$ is the quantity of the intermediate good $i$ that is produced with the final good, in a one-to-one proportion. The elasticity of substitution between varieties is $\varepsilon=1 /(1-\alpha)>1$ with $\alpha<1$. Physical capital is only used for the production of final goods. For simplicity, we neglect physical capital depreciation, which leads to the economy resource constraint:

$$
Y=C+\dot{K}+\int_{0}^{n} x_{i} d i
$$

With population growth, we must re-write previous equations in per capita terms. The growth rate of population is exogenous and equal to $\dot{P}=b^{n} P$, in which $b^{n}$ is the "net birth rate", that is, the rate of newborns less the rate of mortality. We will denote per capita variables as the respective lower cases. Growth rates of per capita variables are the growth rate of aggregated variables less "net birth rate" or the growth rate of population.

The market for final good and its factors are perfectly competitive and its price is normalized to one. Profit maximization, taking $r, p_{D}$ and $w$ as given, implies the following inverse-demand functions:

$$
\begin{gathered}
r=\frac{\beta Y}{K}, \\
p_{D}=\frac{\eta Y}{D},
\end{gathered}
$$

and

$$
w=\frac{(1-\beta-\eta) Y}{H_{Y}},
$$

where $p_{D}$ represents the price index for intermediates.

Each firm in the differentiated goods sector owns a patent for selling its variety $x_{i}$. Producers act under monopolistic competition and maximize operating profits 


$$
\pi_{i}=\left(p_{i}-1\right) x_{i}
$$

The variable $p_{i}$ denotes the price of an intermediate and 1 is the unit cost of $Y$. From profit maximization in the intermediate goods sector, facing elasticity of demand $\varepsilon_{x}=1 /(1-\alpha)$, each firm charges a price

$$
p_{i}=1 / \alpha .
$$

With identical technologies and symmetric demand, the quantity supplied is the same for all goods, $x_{i}=x$. Hence, equation (8) simplifies to

$$
D=n^{1 / \alpha} x .
$$

From $p_{D} D=p x n$ together with equations (14) and (15) we obtain the total quantity of intermediates employed as

$$
X=x n=\alpha \eta Y .
$$

After insertion of equations (14) and (16) into (13), profits can be rewritten as a function of aggregate output and the number of existing firms:

$$
\pi=(1-\alpha) \eta Y / n .
$$

Before we proceed with the analysis we compute some equations that will be useful at the three stages of development that we will analyze. Insertion of equation (16) in equation (9) simplifies the resource constraint to

$$
\dot{K}=(1-\alpha \eta) Y-C
$$

and insertion of (15) and (16) in the production function (7) gives the output growth rate in per capita terms:

$$
(1-\eta) g_{y}=\beta g_{k}+\left[\frac{1-\alpha}{\alpha}\right] \eta g_{n}+(1-\beta-\eta)\left(g_{u_{1}}+g_{h}\right)
$$

where $u_{1}=h_{Y} / h$ is the proportion of knowledge allocated to final good production and where the growth rate of variable $z$ is denoted by $g_{z}$. Log-differentiation of equations (10) and (12) provides

$$
\begin{gathered}
g_{r}=g_{y}-g_{k} \\
g_{w}=g_{y}-\left(g_{u_{1}}+g_{h}\right)
\end{gathered}
$$




\subsection{Households}

Each individual allocates his knowledge between the different activities in the economy, such that:

$$
h=h_{H}+h_{n}+h_{Y}
$$

Individuals earn wages, $w$, per unit of employed labor $\left(h-h_{H}\right)$ and returns, $r$, per unit of individual wealth. They maximize intertemporal utility $U_{t}=\int_{t}^{\infty} \frac{c_{t}^{1-\theta}-1}{1-\theta} e^{-\left(\rho-b^{n}\right)(\tau-t)} d \tau$, where $\rho>0$ denotes the time preference rate, subject to $\dot{a}=w\left(h-h_{H}\right)+\left(r-b^{n}\right) a-c$ and to the per capita version of (1). ${ }^{6}$ Using the control variables $c>0$ and $h_{H} \geq 0$ and the state variables $a$ and $h$, we write the current value Hamiltonian

$$
\Xi=\frac{c_{t}^{1-\theta}-1}{1-\theta}+\lambda_{1}\left(w\left(h-h_{H}\right)+\left(r-b^{n}\right) a-c\right)+\lambda_{2}\left((\xi-\gamma d) h_{H}-b^{n} h\right)
$$

and obtain from its first order conditions, the following expressions for consumption and wage growth rates:

$$
\begin{gathered}
\frac{\dot{c}}{c}=\frac{r-\rho}{\theta} \Leftrightarrow \frac{\dot{C}}{C}=\frac{r-\rho}{\theta}+b^{n} \\
h_{H}>0 \text { and } \frac{\dot{w}}{w}=(r-\xi+\gamma d) \text { or } h_{H}=0
\end{gathered}
$$

Equation (23) is the standard Ramsey rule. Equation (24) indicates that the growth rate of wages must be sufficiently high compared to the interest rate to ensure investment in human capital.

In the following sections we describe the evolution of the economy from a Cass-Koopmans model to a human capital accumulation model and then to an R\&D model of endogenous growth. First, we will present the steady-states of transitory stages and the final steady state. Then, we present equations that characterize the model dynamics and that we use to simulate the model.

\section{The evolution of the Economy through stages and the impact of Mortality and Property- Rights}

In the steady state, there are no factor movements between sectors, which implies that $g_{u_{1}}=0$, and we face a constant real interest rate $\left(g_{r}=0\right)$. Using $(20)$

\footnotetext{
${ }^{6}$ Although individuals have finite lives, we consider an immortal extended family that makes intergenerational transfers based on altruism (see Barro and Sala-i-Martin (1995:60))
} 
and (21) in (19), we get $g_{y}=\frac{1-\alpha}{\alpha} \frac{\eta}{1-\eta-\beta} g_{n}+g_{h}$. In the first stage, we assume $g_{n}=g_{h}=0$, which also gives zero growth rate of GDP per capita in the steady state. ${ }^{7}$ In the second stage $g_{n}=0$ but $g_{H}>0$. Substituting $g_{h}$ with $g_{y}-g_{w}$ (from (21)) and $g_{w}$ by the value given in (24), we obtain the interest rate in this transitory equilibrium. Using (18), we know that $g_{y}=g_{c}$ and by (23) we reach $g_{y}$ in this transitory equilibrium, which is given by $g_{y}=\frac{\xi-\gamma d-\rho}{\theta}$. Finally, in the third stage, by (2) and the fact that in equilibrium there are no factor movements between sectors, we find that the growth rate of aggregate human capital is equal to the growth rate of the number of varieties in the steady state $\left(g_{n}=g_{H}\right)$. Thus (19) may be re-written as $g_{y}=\left(1+\frac{1-\alpha}{\alpha} \frac{\eta}{1-\eta-\beta}\right) g_{h}+\frac{1-\alpha}{\alpha} \frac{\eta}{1-\eta-\beta} b^{n}$. Using again (21) held $g_{y}$ in the steady state. Results for the two transitory steady-states and for the steady state are summarized in the next table.

Table 1: Steady-states of transitory stages and final Steady-state

\begin{tabular}{|c|c|c|}
\hline $1^{\text {st }}$ Stage & $2^{\text {nd }}$ Stage & $3^{r d}$ Stage \\
\hline$g_{y}=g_{k}=g_{c}=0$ & $\begin{array}{c}g_{y}=g_{k}=g_{c}=g_{h}= \\
=\frac{\xi-\gamma d-\rho}{\theta}\end{array}$ & $\begin{aligned} & g_{y}=g_{k}=g_{c}= \\
= & \frac{(\xi-\gamma d-\rho)\left(1+A_{2}\right)+b^{n}}{(\theta-1)+\theta A_{2}}\end{aligned}$ \\
\hline$g_{h}=g_{n}=0$, by definition & $g_{n}=0$, by definition & $\begin{array}{c}g_{h}+b^{n}=g_{n} \\
=\frac{(\xi-\gamma d-\rho) A_{2}+\theta A_{2} b^{n}}{(\theta-1)+\theta A_{2}}\end{array}$ \\
\hline
\end{tabular}

$$
\text { Note: } A_{2}=\frac{\alpha(1-\beta-\eta)}{(1-\alpha) \eta} \text {. }
$$

It is worth noting that although mortality rate $(\gamma, d)$ directly influences steady-state growth rates, the erosion of monopoly power $(p)$ for new ideas does not.

In the next few lines, we explain why the mortality rate influence can be seen through the different channels that were pointed out in the literature: the health channel; the parental investment channel; and the returns channel, the first of which was discussed earlier, when the human capital accumulation function was presented. We can use the expression for $g_{h}$ to calculate the effort in human capital accumulation $\left(u_{H}=\frac{h_{H}}{h}\right)$. This is useful for confirming that this function also describes the parental investment channel, as was claimed above, according to which mortality affects human capital accumulation because investment in each child increases when mortality decreases. Thus, in the second stage $u_{H}=\frac{1}{\theta}\left(1-\frac{\rho}{\xi-\gamma d}\right)+\frac{b^{n}}{\xi-\gamma d}$ and in the third stage $u_{H}=\frac{A_{2}}{(\theta-1)+\theta A_{2}}\left[\left(1-\frac{\rho}{\xi-\gamma d}\right)+\frac{\theta b^{n}}{\xi-\gamma d}\right]$. The first term in each of the expressions represents the individual effort and the second term represents the effort that results from exogenous population growth. This shows that the individual effort depends negatively on the mortality rate. These expressions are, in fact, quite similar to expression (14) in Zhang et al. (2001), who treat fertility as exogenous, in which parental investment in children's human capital is given as

\footnotetext{
${ }^{7}$ Steady-state in this stage can be defined as a poverty-trap.
} 
a function of fertility (with a negative effect), of the discount factor and of the human capital share in the final production.

Moreover, the parameter $\gamma$ also affects human capital accumulation through returns in the future. In this model, the way of analyzing this effect is to calculate the effect of this crucial parameter on the growth rate of wages. Let us concentrate on the steady-state expression $g_{w}=r-(\xi-\gamma d)=\frac{(\xi-\gamma d)+\theta b^{n}-\rho}{(\theta-1)+\theta A_{2}}$. As $\frac{\partial g_{w}}{\partial \gamma}<0$, the human capital sensitivity to the mortality rate has a negative influence on the growth rate of wages. Kalemli-Ozcan et al. (2000) uses an alternative approach to measure the impact of mortality rate on human capital accumulation in an overlapping generations model, which consists of considering a probability of being alive at each date (given by a Poisson process), which increases the discount rate. Furthermore, it uses the assumption of perfectly competitive annuity business, which implies that lenders will account for the probability of each borrower dying in calculating their marginal cost. ${ }^{8}$

In conclusion, we see that our parameter summarizes the overall effect of the mortality rate on human capital accumulation through the three channels that have been cited to link both phenomena. In the next section we describe the model dynamics.

\section{An Historical Interpretation}

Besides other possible "economic histories", we think that this article offers a good explanation the history of the developed world, beginning in a stage described by a Cass-Koopmans model, where growth can be explained exogenously (either with a temporary or permanent growth rate of technology) to a human-capital accumulation model and then to an R\&D model. ${ }^{9}$ This period can be characterized by the following main facts:

1. Permanent growth had began in England after 1760 (Crafts, 1995).

2. Development can be divided into three stages, according to investment in different assets. Researchers have supported that first there is an increasing role for human capital and then an increasing role for R\&D. Each stage brings up the economic growth rate (Maddison, 1995; Crafts, 1995, 1996; Pereira, 2003, S $\phi$ rensen, 1999).

3. The last R\&D period has been the lengthiest (Crafts 1995, Maddison, 2001).

\footnotetext{
${ }^{8}$ It can be shown that their approach is qualitatively similar to ours. Consider that $d$ is the probability of dying at each unit time ( $\rho$ in their notation), then $e^{-d t}$ is the probability of being alive at each unit time. Consider also that the net interest rate will be $r+d$. Then the growth rate of wages is equal to $r+d-\xi$, which compares with our equation (24). The growth rate of consumption is given by our (23). Thus the effect of $d$ is qualitatively equal to the effect of $\gamma d$ in our model.

${ }^{9}$ Before the Cass-Koopmans-Ramsey model, the economy is described as a Malthusian economy (Hansen and Prescott, 2002 and Pereira, 2003).
} 
4. Mortality decline is related with human capital investment and growth (Kalemli-Ozcan, 2002 and Kalemli-Ozcan et al., 2000, among others).

The last two periods can be easily identified in the data (see for instance S $\phi$ rensen, 1999). However, support for an initial stage in which the economy engine of growth is only physical capital is more difficult to obtain. Nevertheless, Crafts' (1995) growth accounting for the British industrial revolution shows little role for human capital and TFP in the period from 1760 to 1780 . Moreover, macroinventions, best seen as exogenous technological shocks, were crucial to the beginning of economic growth in the British Industrial Revolution, which excludes endogenous growth models from the explanation of the first industrial times. We first admit that this was the case as, for instance, in Galor and Moav (2003).

Also controversial in economic history is the division between periods.

The first division consists of setting a time interval in which human capital growth began. In a growth accounting exercise performed by Crafts (1995) human capital contribution rose from $17 \%$ (from a $10 \%$ growth rate) in 1760 1780 period to $26 \%$ (from a $20 \%$ growth rate) and $30 \%$ (35\% growth rate) in the following periods (1780-1831 and 1831-1873), respectively. However, according to this author, male literacy only begins to rise after 1801 and maintenance or even decrease of skills-per-worker occurred in the early British industrial revolution. It is also worth noting that the high and volatile mortality rate until 1750 in England (and consequently slow population growth) could have played a role as an incentive to begin the accumulation of human capital in the next stage through increasing wages (evidence is from Mokyr, 1990). This incentive can be seen in equation (24), with $r=\rho .{ }^{10}$ Crafts (1996), citing Mokyr, argued that microinventions, seen as adaptations of macroinventions to production, led by learning-by-doing practices, constituted the comparative advantage of Britain: "Given that learning within a particular technology is bounded, sustaining faster growth requires both new inventions" - the macroinventions - "and an ability to transfer learning to new technologies" - the microinventions (Crafts, 1996). So human capital contribution to growth, given that we argued for the existence of a first physical capital stage, began between 1780 and 1800 . Thus, the first period length seems to last about 20 to 40 years, according to the belief of economic historians.

The second division consists of setting a time interval to initial investments in R\&D. The upper bound for this interval is between 1870 and 1890 , a period in which historians date the beginning of the American industrial revolution, which is undoubtedly more $\mathrm{R} \& \mathrm{D}$-intensive than the British one, as was recognized by Maddison (1995). The lower bound depends on the answer to the following question: is there a scope for an endogenous R\&D explanation for the British Industrial Revolution? Arguments in favor of an explanation based on R\&D

\footnotetext{
${ }^{10}$ Some authors cited in Lindert (1994) found that wages of skilled workers had increased when compared with non-skilled between 1750 and 1790 in some English regions. It is after 1740 that life expectancy shows an increasing trend, but it is only after 1800 that this trend had not been affected by dramatic falls in some years (Schofield, 1994).
} 
endogenous growth models, at least for the final years of the British industrial revolution, are strong. As Crafts (1996) supported, "Britain had an unusual proficiency for importing ideas and improving upon them; government policy recognized the importance of (...) technology transfer. A striking feature of the early 19th-century Great Britain was the mushrooming of associations that were designed to spread technological progress".

In conclusion, we can set an interval between 1780-1800 and 1820-90 for the human capital accumulation stage, which means that this period may last for 20 to 110 years. The corresponding lengthier period for the third innovative stage is according to the view of Crafts $(1995,1996)$.

Another interesting feature of the model is that per capita GDP growth rate depends positively on the population's rate of growth. This comes from the use of human capital in research and increasing returns to scale in the final product $(\mathrm{Y})$ when the number of varieties is included $\left(1+\eta\left(\frac{1-\alpha}{\alpha}\right)>1\right)$. As the population grows, more people are employed in R\&D activities, increasing the number of varieties available for each family. This is also found by Jones (2001) and is empirically consistent, as Kremer (1993) has shown. This differs from this author's view in one aspect: this model does not predict a link between the initial level of population and economic growth. This feature fits, for instance, the episode of the second industrial revolution in the USA, where growth was not related with initial population but with massive entrance of immigrants, i.e., population growth. ${ }^{11}$ Slow population growth $(1.6 \%$ per year between 1870 and 1900) may also explain the decreasing performance of England after 1870.

Increasing growth rates of GDP per capita throughout stages of development, due to the accumulation of human capital (between the first and the second stage) and due to a research-effect (from the second to the third stage) are also in line with reported data: this effect occurred in the United Sates, which showed a per capita growth rate of GDP of $2.2 \%$ between 1980 and 1998, compared with a rate of $1.3 \%$ between 1820 and $1870 .{ }^{12}$

The model fits with this historical description. The Cass-Koopmans model describes the first period (with a length of nearly 20 years). This is a period where "endogenous" economic growth has not taken place, but Macroinventions (seen as exogenous) may lead to permanent but slow growth. After Microinventions took advantage in England hand to hand with increasing literacy/training and demographic transition (declining mortality rates), the economy begins to resemble as a Lucas-type human capital model (with a length of between 20 and 110 years). After that, TFP contribution permanently increased either in UK and in USA and the economy can better be described as a semi-endogenous model of R\&D with a positive contribution of population growth to economic growth.

\footnotetext{
${ }^{11}$ The population in the USA was near below 5 million in 1800 . However, this number rose to 40 million in 1870. Between 1870 and 1900, population in the USA had grown $2.9 \%$ per year. This simply means that the USA doubled its population between these years.

${ }^{12}$ However, there is also the theoretical possibility of having higher per capita growth rates in the second stage than in the third with decreasing population.
} 
At this stage, we can say that steady-states of transitory stages, final steadystate and the qualitative evolution of the economy throughout stages of development are close to what is described by economic history for this period. This was our first test of the model.

In the next section we describe the model dynamics.

\section{The Model Dynamics}

We will now evaluate the length of these periods according to the proposed model. For that, we first present equations that describe the dynamics of the model and that we use in simulation (Section 4.1). Then we explain the simulation procedure (Section 4.2) and finally, we present the results of simulation (Section 4.3).

\subsection{The Evolution of the Economy through stages}

\subsubsection{The first stage or the Cass-Koopmans Model}

We summarize the equations that describe the dynamic in this stage, in which the economy only invests in physical capital. Let $C / K$ denote the consumptioncapital ratio. Because the economy is investing only in physical capital, from (20) and (19), using (10) and (18), we can write $g_{r}$ as:

$$
g_{r}=-\frac{1-\beta-\eta}{1-\eta}\left(\frac{1-\alpha \eta}{\beta} r-C / K\right)
$$

and from the definition of $C / K$, using (10), (23) and (18):

$$
g_{C / K}=\left(1 / \theta-\frac{1-\alpha \eta}{\beta}\right) r+C / K-\rho / \theta+b^{n}
$$

It is worth noting that the economy begins investing only in physical capital, but due to decreasing returns to capital, we can see from (20) and (21) that $r$ is decreasing (and converging to $\rho$ ) and $w$ is increasing with $y$ in the adjustment path.

\subsubsection{The second stage or the Uzawa-Lucas Human Capital Model}

In this stage we describe a situation in which $H$ is growing $(\dot{H}>0)$. For that purpose we now assume that $g_{n}=0$ and then $h_{H}=\left(1-u_{1}\right) h$. With this we can summarize the dynamics of eqs. (19) to (21) to

$$
g_{r}=-[(1-\beta-\eta) / \beta](r-\xi+\gamma d)
$$

Since $\partial g_{r} / \partial r<0$, the interest rate converges to $\xi-\gamma d$ independently of the remaining system dynamics. From equation (10) and (18) we obtain 


$$
g_{K}=[(1-\alpha \eta) / \beta] r-C / K
$$

from which, with equation (23), we can again get (26).

Then from equations (1) and (28)

$$
g_{K / H}=[(1-\alpha \eta) / \beta] r-C / K-\left(1-u_{1}\right)(\xi-\gamma d)
$$

which is independent of $K / H$. From equations (20) and (21) we compute $g_{u_{1}}=$ $g_{K / H}+g_{r}-g_{w}$ and hence after insertion of equations (24), (27) and (29) we obtain

$$
g_{u_{1}}=[(1-\alpha) \eta / \beta] r-C / K+(\xi-\gamma d) u_{1}+[(1-\eta-\beta) / \beta](\xi-\gamma d)
$$

The system dynamic is described by the set of differential equations in $\mathrm{r}, C / K$ and $u_{1}$ given by (27), (26) and (30) respectively. Stationary equilibrium in this stage is characterized by $r^{*}=\xi-\gamma d, u_{1}^{*}=1-(\xi-\gamma d-\rho) /(\theta(\xi-\gamma d))$, and $C / K^{*}=[(1-\alpha \eta) / \beta](\xi-\gamma d)-(\xi-\gamma d-\rho) / \theta-b^{n}$. Thus the equilibrium of this stage is negatively affected by bad institutions: high mortality rate driven by poor health care and sanitation services and low incentives to education, which lead to a high influence of the mortality rate.

Notice now that the growth rate of profits is growing with GDP per capita (see eq. (17)) but the wage (the R\&D cost) is growing less than GDP per capita (due to human capital accumulation - see eq. (21)), which is an incentive to begin investing in R\&D. The next proposition states that in equilibrium, the economy always begin investing in R\&D. ${ }^{13}$

Proposition 1 If individuals invest in human capital (which occurs if $\xi-\gamma d>$ $\rho)$, the economy will invest in RED at some period in time.

Proof. At the steady state $r$ is constant and, from (3), $v$ may be calculated as $v_{t}=\pi_{t} /\left(\rho+p+g_{n}\right)$. For $g_{n}=0$, this implies that $g_{v}=g_{\pi}=g_{Y}$. So, for $g_{H}>0, g_{v}>g_{w}$. This implies that, though initially $w>\epsilon v$, at some period in time we must have that $w=\epsilon v$.

\subsubsection{The third stage or the Grossman-Helpman-Jones R\&D Model}

In this stage of development, the country is investing in all of the available assets. For an innovative economy with knowledge accumulation, eq. (4) must hold. Using eq. (4), equation (6) can be re-written as

$$
g_{w}=r+p-\epsilon \pi / w
$$

\footnotetext{
${ }^{13}$ For convergence characteristics of the Uzaca-Lucas type model we refer to literature (Barro and Sala-i-Martin, 1995, p. 184-188).
} 
After substitution of profits from eq.(17), wages from eq.(12) and the growth rate of wages from eq.(24) into equation (31), we obtain the human capital share in final good production:

$$
u_{1}=\frac{\xi-\gamma d+p}{\epsilon} \frac{(1-\beta-\eta)}{(1-\alpha) \eta} \frac{n}{H}
$$

This implies that $g_{u_{1}}=g_{n}-g_{H}$. From this equation and eq.(21) the growth rate of innovations can be written as $g_{n}=g_{Y}-g_{w}$. Insertion of eqs.(20) and the last two into eq.(19) provides the growth rate of the interest rate according to:

$$
\left(1-\frac{1-\alpha}{\alpha} \frac{\eta}{\beta}\right) g_{r}=-\left[\frac{1-\alpha}{\alpha} \frac{\eta}{\beta}+\frac{(1-\beta-\eta)}{\beta}\right] g_{w}+\frac{1-\alpha}{\alpha} \frac{\eta}{\beta} g_{K}
$$

or after substituting $g_{w}$ and $g_{K}$ from equations (24) and (28),

$$
\begin{aligned}
\left(1-\frac{1-\alpha}{\alpha} \frac{\eta}{\beta}\right) g_{r} & =\left\{\frac{1-\alpha}{\alpha} \frac{\eta}{\beta}[(1-\alpha \eta) / \beta-1]-\frac{(1-\beta-\eta)}{\beta}\right\} r- \\
& -\frac{1-\alpha}{\alpha} \frac{\eta}{\beta} C / K+\left[\frac{1-\alpha}{\alpha} \frac{\eta}{\beta}+\frac{(1-\beta-\eta)}{\beta}\right](\xi-\gamma d)
\end{aligned}
$$

To reveal the dynamics of the knowledge formation, we define the knowledgeideas ratio as $H / n$ and obtain from equations (1), (2), and (32):

$$
g_{H / n}=(\xi-\gamma d)\left[1-\left((\xi+p-\gamma d) A_{2} / \alpha+g_{n}\right)(n / H) / \epsilon\right]-g_{n}
$$

The dynamics of the model can be characterized by (26), (34) and (35). Therefore we can characterize steady state as

$$
\begin{gathered}
r^{*}=\frac{\theta(\xi-\gamma d)\left(1+A_{2}\right)-\rho+\theta b^{n}}{(\theta-1)+\theta A_{2}}, \\
C / K^{*}=\rho / \theta+\left(\frac{1-\alpha \eta}{\beta}-1 / \theta\right) r^{*}-b^{n}
\end{gathered}
$$

which implies that

$$
\begin{aligned}
g_{n}^{*} & =g_{H}^{*}=g_{Y}^{*}-g_{w}=\frac{r-\rho}{\theta}-(r-(\xi-\gamma d))= \\
& =\frac{(\xi-\gamma d-\rho) A_{2}+\theta A_{2} b^{n}}{(\theta-1)+\theta A_{2}}
\end{aligned}
$$

and

$$
H / n^{*}=\frac{(\xi-\gamma d)}{\epsilon} \frac{\left(\frac{A_{2}}{\alpha}\right)(\xi+p-\gamma d)+g_{n}^{*}}{\xi-\gamma d-g n^{*}}
$$

where $A_{2}$ has been defined earlier. These steady-state equations are our initial point for the backward-integration procedure that we explain below. ${ }^{14}$

\footnotetext{
${ }^{14}$ For convergence features, we again refer to literature (Arnold, 1998, for instance).
} 


\subsection{Simulating the Model Economy}

We now present the results of a calibration and simulation exercise of the model presented above. In the first sub-section, we describe the simulation procedure. In the second sub-section, we describe the benchmark calibration and departures from this calibration. For that, we also summarize each of the extensions, for which we present the results in the following sub-section, in which we try to replicate the main features of world development in the last two centuries.

\subsubsection{Simulation procedures}

We proceed by backward integration (as described in Brunner and Strulik (2002)) and integrate the model of economic growth described above. We begin arbitrarily close to the steady state of the last stage (the innovative economy) and we backward integrate the equation that describes the evolution of $C / K$ (26), the equation that describes the evolution of $r$ in the same stage (34) and that which describes the evolution of $H / n(35)$, until we reach a value for the share of human capital in research $\left(H_{n} / H\right)$ equal to zero. At this point the economy reaches (backward looking) the UL environment. Beginning now with the first values for $r, C / K$ and $u_{1}$ for which $H_{n} / H>0$, we backward integrate the equation that describes the evolution of $r$ in the second stage (27), (26) and the equation that describes the evolution of the share of human capital affected by the final good production (30), stopping when $H_{H} / H=0$. At this point the economy reaches (backward looking) the Cass-Koopmans economy. Beginning in the first values for $r$ and $C / K$ for which the share of human capital in education is less than one, we backward integrate the equation for the evolution of $r$ in the first stage (25), and the equation for the evolution of $C / K$ in the first stage (26) until reaching a sufficiently high value for the interest rate. ${ }^{15}$ Because this value for the interest rate affects the length of the first stage, we have to be cautious in analyzing the length of this stage and focus only on differences that arise from different extensions. Initial values for this variable can, however, be adjusted without changing the following path of the economy. Values for variables in levels $\left(y_{t}, c_{t}\right.$, etc.) are obtained using the trapezoid rule, using the respective growth rates. For practical reasons, we consider that the economy reaches the steady state when all growth rates in the economy present constant figures with 6 decimal digits approximation.

\subsubsection{Calibration}

Most parameters for our exercises were taken from Funke and Strulik (2000), except Population Growth and Mortality rate that were borrowed from Kremer

\footnotetext{
${ }^{15}$ We have used a value of 1.7 times the value of the interest rate at the transition between the first and the second stage. Experiments that change this and set a fixed difference between this value and the steady state (of the last stage) value do not show significant quantitative changes in our results. We employ a fourth-order Runge-Kutta method with variable step control provided by Matlab. We applied a maximum discretization error of $10^{-11}$. Matlab codes are available upon request.
} 
(1993) and Jones (2001), respectively, and the sensitivity of human capital to mortality rate $(\gamma)$ is made to replicate the actual level of GDP per capita in 1998, beginning with its actual level in 1760 . We have averaged population growth rate from 1750 and 1990 using data from Kremer (1993, Table 1), and the value for population growth is $0.83 \%$. This is in the same variable range showed by Jones (2001, Table 8), which corresponds to levels of per capita consumption between 948 and 20,000. According to Jones (2001), mortality rate is between $4 \%$ and $0.7 \%$, between 800 and 20,000 international dollars in per capita consumption. We will assume a median value of $2 \%$. According to Maddison (2001), GDP per capita the industrialized world (western Europe, USA, Canada, New Zealand, Australia and Japan) in 1760 was 1012 international 1990 dollars. ${ }^{16}$ In 1998, according to the same source, per capita income was 21,470. In the absence of empirical data for the probability of patent loss $(p)$, we consider $p=0$ in the benchmark analysis, although probably the real economy has $p>0 .{ }^{17} \mathrm{We}$ conclude that other assumptions about $p$ cannot crucially change the results. We choose as the benchmark exercise the replication of per capita average growth rate of GDP in the industrialized world. The next table summarizes parameters for the benchmark calibration.

Table 2: Calibration for the Benchmark Analysis

\begin{tabular}{cc}
\hline Parameters & Values \\
\hline$\alpha$ & 0.54 \\
$\beta$ & 0.36 \\
$\eta$ & 0.36 \\
$\epsilon$ & 0.1 \\
$\xi$ & 0.05 \\
$\rho$ & 0.023 \\
$\theta$ & 2 \\
$d$ & 0.02 \\
$b^{n}$ & 0.0083 \\
$p$ & 0 \\
\hline
\end{tabular}

We will consider various extensions to this calibration. We present results for (1) the industrialized world without the first stage, (2) an economy with higher shares of physical capital in the first stage, (3) an economy with spillovers ${ }^{18},(4)$

\footnotetext{
${ }^{16}$ This was obtained applying the average growth rate between 1700 and $1820(0.18 \%)$ to GDP per capita in 1700 (907 international dollars) - Table 1-9a, p.46.

${ }^{17}$ According to current legislation, patent length is from 17 years (in USA) to 20 years (in Europe). Using a certainty equivalence expression between the length of patents and the erosion of monopoly probability - $p$ - we can achieve values for $p$ between 0.031 and 0.039. However, we lack information about the evolution of this length and the effectiveness of legislation in past periods. It is also said that bureaucratic processes may decrease effective protection. For our proposes, the advantage of using a total protection assumption $(p=0)$ in the benchmark exercise is that effects of differences in $p$ from an initial value of zero are higher than from initial positive values. This is appropriate (and also more demanding for our exercise) as we will argue that the effect of mortality is higher than that of property rights. Results with an initial $p=0.05$ (corresponds to 14 years of protection) are fairly similar to those presented in the text, and are available upon request.

${ }^{18}$ For which a model is developed in Appendix A.
} 
an economy with demographic transition and (5) the evolution of the United Kingdom economy. As we explain in greater detail below, with more detail, extension (1) is made to avoid the arbitrary chosen initial value for the real interest rate, extension (2) is made to replicate growth rates in the first stage, extensions (3) and (4) to introduce important features of the real world. In all the extensions we approximate the actual value for GDP per capita in 1998 and obtain the value of the sensitivity of human capital accumulation to the mortality rate $(\gamma)$ that fits that value. The next table summarizes changes in parameters for each extension.

Table 3: Departures from the Benchmark Calibration

\begin{tabular}{cccccc}
\hline & $Y_{0}$ & $\beta$ & $d$ & $b^{n}$ & $Y_{1998}$ \\
\hline Benchmark & 1012 & 0.36 & 0.02 & 0.0083 & 21470 \\
Without First Stage & 1049 & 0.36 & 0.02 & 0.0083 & 21470 \\
Capital Share & 1012 & $0.51^{*}$ & 0.02 & 0.0083 & 21470 \\
Spillovers $(\phi=0.2)$ & 1012 & 0.36 & 0.02 & 0.0083 & 21470 \\
Demographic Transition & 1012 & 0.36 & $0.04 ; 0.04 ; 0.015$ & $0.0044 ; 0.0057 ; 0.0106$ & 21470 \\
\hline
\end{tabular}

Notes: $\mathrm{Y}_{0}$ and $\mathrm{Y}_{1998}$ are calculated according to Maddison (2001), $\mathrm{Y}_{0}$ in the third extension is $\mathrm{Y}_{1780}$, the values for $d$ and $b^{n}$ in the last extension are values for the three stages, respectively.

* The share of physical capital is only changed in the first stage.

The value for the share of physical capital in the "Capital Share" extension was made to replicate lower growth rates in the first stage. ${ }^{19}$ In particular, we choose $\beta=0.51$ to replicate a zero growth rate in the last year of the first stage. The value for spillovers was set to 0.2 because higher values are not possible in an equilibrium with human capital investment. ${ }^{20}$ For the demographic transition, we have used data from Kremer (1993) (for the population growth) and from Jones (2001) (for the mortality rate). For the population growth, we have averaged figures for three periods available that we have associated with our three stages of development: 1750-1800, 1800-1850 and 1850-1990. ${ }^{21}$ For mortality rate, we have chosen a value of $4 \%$ for the first two stages and a value of $1.5 \%$ for the last stage. The first value is due to Livi-Bacci (1997), which supports that average mortality rates range as high as 4 to $5 \%$ between 1 and 1750 A.D.. Thus we choose the lower bound of this interval to roughly describe

\footnotetext{
${ }^{19}$ As for King and Rebelo (1993), this parameter has crucial importance in reaching lower interest rates - in their case - and faster or slower convergence in the neoclassical economy. In our case it reaches lower output growth rate but as a consequence of slow convergence, the economy lasts longer before investing in human capital.

${ }^{20}$ Arbitrage condition between knowledge (human capital) and ideas imply that for an equilibrium with investment in these two assets we must not have huge differences in productivities. In fact, recent evidence which includes the effect of human capital, suggests much smaller domestic - near 55\% smaller - and international spillovers - from 35\% to $85 \%$ smaller - than those suggested by previous literature without human capital (Barrio-Castro et al., 2002).

${ }^{21}$ This is the possible association according to available data.
} 
the period between 1760 and 1780 . The value for the last stage is a mean point between the values pointed out by Jones (2001) for the periods 1950-55 and 1985-90.

\subsection{Replicating the Evolution of the World Economy}

Here, we want to replicate the main features of the evolution of the developed world in the last two centuries in order to obtain a value of $\gamma$ (the sensitivity of human capital to the mortality rate) that allows for good replication results, so that we can further use the model to compare the relative impact of mortality rate and property rights. ${ }^{22}$ First, we show the evolution of growth rates and other variables in our benchmark specification. Second, we show that the effect of mortality rate on human capital accumulation is crucial for this model to replicate the evolution of the real economy. Then, we obtain the length of each stage and the implied value of the sensitivity of human capital accumulation to the mortality rate in order to match the actual value of GDP per capita. We do this for all of the extensions described above. Figure 2 summarizes the evolution path for the benchmark economy.
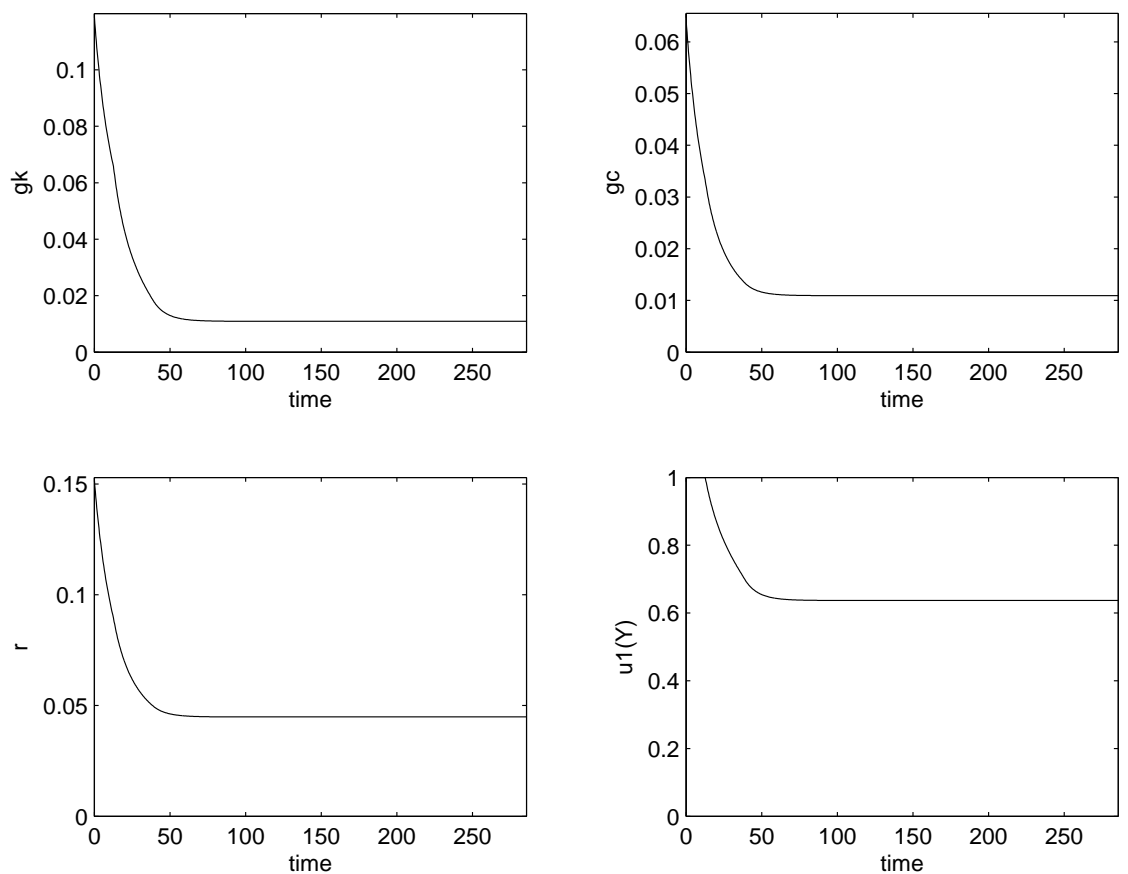

${ }^{22}$ We use $\gamma$ as the instrument to mimic the real world because variations in $p$ are not capable of doing it. In fact, it will be shown that huge differences in $p$ have a low influence in transitional dynamics and on the final situation. 

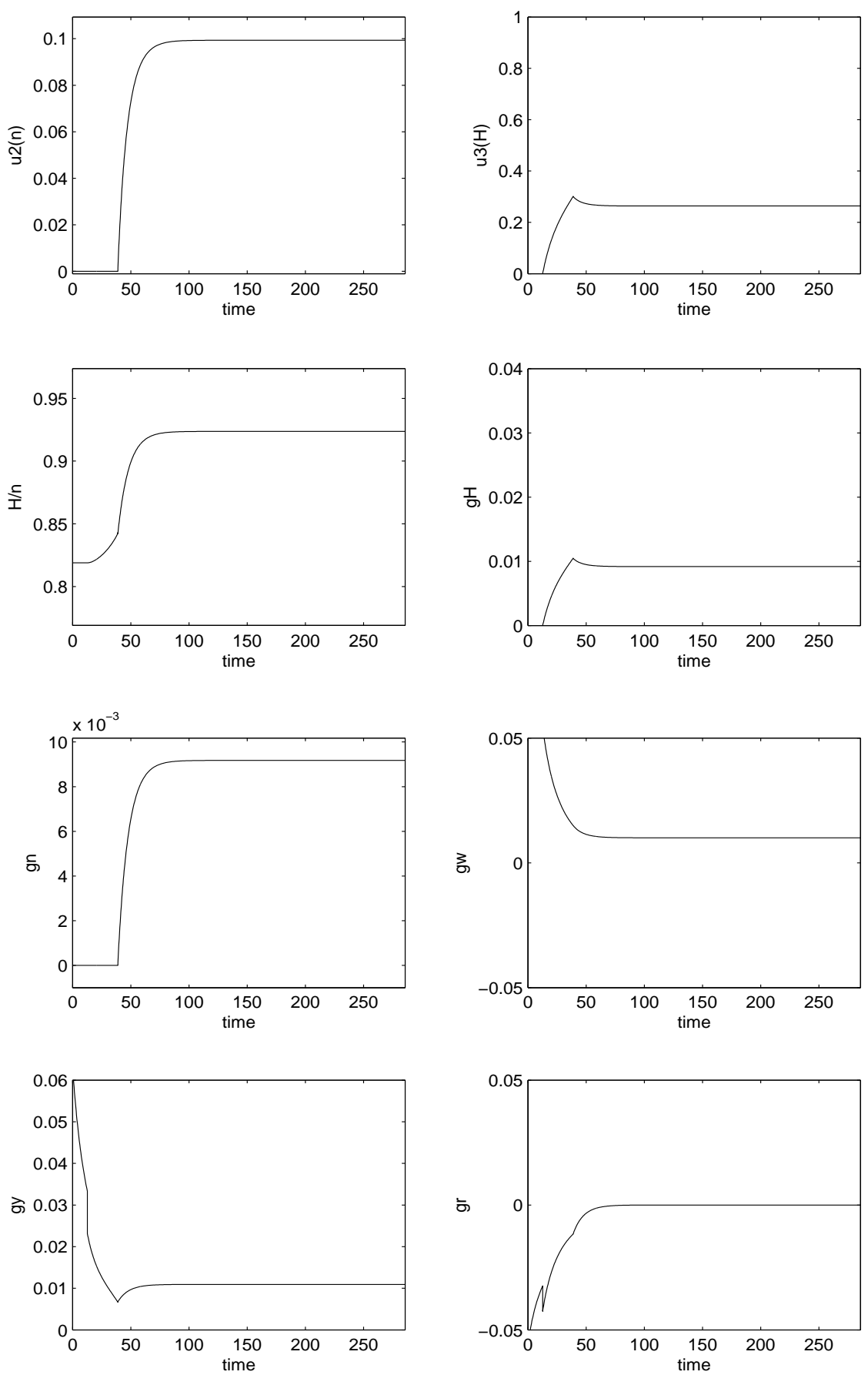

Figure 2. Transition Path for the Benchmark Economy 
The evolution of the economy is characterized by a large transition before reaching the final steady state (more than one hundred years), which mainly occurs when agents are investing in R\&D, until a steady state, in which GDP per capita is growing at $1.1 \%{ }^{23}$ This transition represents $33 \%$ of the per capita GDP increase until 1998. In the first stage GDP per capita growth rates are decreasing but quite high. It is worth noting that between the second and third stages, this growth rate increases due to research. It continues on an increasing path until it reaches the steady state. In the first stage there is no investment in R\&D, nor in human capital. However, we see that the interest rate (panels 3 and 12 ) is decreasing (from an initial value of $15 \%$ ) and wages are growing (panel 10), providing incentives to begin investing in human capital. ${ }^{24}$ In the second stage, increasing GDP per capita and decreasing wages - see Panels 10 and 11 in Figure 2, about 15 years after the beginning of transition, became the main incentives to invest in R\&D, which began after nearly 40 years. Finally, a note to say that in the second stage, human capital accumulation has two different effects: it contributes to production of the final good and it has an opportunity cost in terms of the final good production because some of the available human capital is affected to increase knowledge in the economy (see panels 4 and 6 in Figure 2).

Table 4.1. summarizes statistics for the stages' length and final GDP in different simulations. The First line presents the replication of Funke and Strulik (2000) exercise: we set $\gamma=b^{n}=0 .{ }^{25}$ The second line presents our benchmark analysis (Benchmark), that was made to replicate the average evolution of GDP per capita in all the industrialized world between 1760 and 1998. The third line presents a simulation that begins in the second stage (roughly in 1780, by means of comparison) - Without $1^{\text {st }}$ Stage. This aims to avoid the possible arbitrary choice of a final value of $r$ for the simulation in the first stage. In this extension, the implied first value for the interest rate is $10.2 \%$. The following line (the fourth one) shows results for a simulation in which a different physical capital share was introduced in the first stage. As was explained, this was done in order to reach more realistic economic growth rates in the first stage. The next two lines show extensions in which features such as spillovers (in the fifth line) - a model with spillovers is presented in appendix - and demographic transition Demo. Trans. - (in the sixth line) were introduced. In the first four columns we show the length of transition in each stage and the total length until the steady state. Then we show the implied value of the sensitivity of human capital accumulation to the mortality rate (the crucial parameter $\gamma$ ) that was made to replicate the actual value of GDP per capita in $1998 .{ }^{26}$ We then show the

\footnotetext{
${ }^{23}$ For the whole world, per capita growth rate between 1973 and 1992 - a period judged as in the steady state - is $1.2 \%$ and for the industrialized world is between $1.4 \%$ (Canada, USA, New Zealand and Australia) and 1.8\% (West Europe) (figures are from Maddison (1995)).

${ }^{24}$ Some have argued that this has, in fact, taken place in eighteenth-century England (see Lindert, 1994).

${ }^{25}$ The exercise replicates Transitional Dynamics in Funke and Strulik (2000): A Qualification at www.rrz.uni-hamburg.de/wst/strulik/fsextra.pdf.

${ }^{26}$ The chosen gama $(\gamma)$ is the two-decimal-points number that turns the predicted GDP per capita as close as possible to the actual one.
} 
predicted GDP per capita in 1998, the proportion of GDP increase verified in transition in overall increase in GDP until 1998 and finally, the first year the economy reaches the steady state.

Table 4.2. summarizes results for growth rates of GDP per capita in the middle and at the end of different stages, for all the cited simulations.

Table 4.1: Features of Model Economies - replication of actual levels of development

\begin{tabular}{ccccccccc}
\hline & \multicolumn{4}{c}{ Transition (Stages) } & $\gamma$ & GDP p. c. & \% GDP in & First year \\
& $1^{\text {st }}$ & $2^{\text {nd }}$ & $3^{\text {rd }}$ & Total & & 1998 & transition & in SS \\
\hline FS (2000) & 15.4 & 19.1 & 62.9 & 97.4 & 0 & 116180 & 7.6 & 1857 \\
Benchmark & 12.7 & 26.2 & 98.4 & 137.3 & 0.76 & 21737 & 32.9 & 1897 \\
W. 1 $^{\text {st }}$ Stage & - & 23.6 & 91.3 & 114.9 & 0.56 & 21222 & 24.2 & 1875 \\
Capital Share & 55.8 & 30.4 & 131.6 & 217.8 & 0.99 & 21543 & 66.5 & 1978 \\
Spillovers & 12.7 & 52.9 & 68.6 & 134.2 & 0.80 & $21161^{*}$ & 31.1 & 1894 \\
Demo. Trans. & 15.6 & 8.6 & 96.1 & 120.3 & 1.03 & 21287 & 25.3 & 1880 \\
\hline
\end{tabular}

Notes: Numbers are in years, with the exception of those in the columns for $\gamma$ and GDP p.c., which is in 1990 international dollars.

*Figures for GDP per capita in these cases are approximate, as growth rates are not constant in 1998.

Table 4.2: Features of Model Economies - growth rates

\begin{tabular}{ccccccc}
\hline & \multicolumn{5}{c}{$1^{\text {st }}$} & \multicolumn{4}{c}{ Growth Rates (Stages) } \\
& Middle & End & Middle & End & Middle & End \\
\hline FS (2000) & $4.3 \%$ & $3.2 \%$ & $1.8 \%$ & $1.4 \%$ & $1.8 \%$ & $1.8 \%$ \\
Benchmark & $4.4 \%$ & $3.3 \%$ & $1.2 \%$ & $0.7 \%$ & $1.1 \%$ & $1.1 \%$ \\
Since 1780 & - & - & $1.5 \%$ & $0.9 \%$ & $1.4 \%$ & $1.4 \%$ \\
Capital Share & $3.0 \%$ & $0 \%$ & $0.9 \%$ & $0.4 \%$ & $0.8 \%$ & $0.8 \%$ \\
Spillovers & $4.4 \%$ & $3.3 \%$ & $0.8 \%$ & $-0.2 \%$ & $1.1 \%$ & $1.1 \%$ \\
Demo. Trans. & $3.8 \%$ & $3.1 \%$ & $-0.1 \%$ & $-0.8 \%$ & $1.2 \%$ & $1.2 \%$ \\
\hline
\end{tabular}

Note: all growth rates are rounded to one decimal point. Middle values are the median time point for each stage.

These tables show some interesting and important results. First of all, the introduction of the mortality rate effect on human capital productivity is crucial to replicating actual economic history over the last two and a half centuries regarding average growth rate of per capita GDP. The exclusion of this feature, as we show in the first line (Table 4.1.), considering $\gamma=0$ and zero growth rate of population, would lead to an unrealistic per capita GDP in any country in the world. In fact, until now, literature (Funke and Strulik (2000) and King and Rebelo (1993), for instance) wants to replicate steady-state growth rates (in the last period) but this procedure is far from replicating actual trajectories in models with large transition paths, as it is shown here. The presence of a setting with the effect of the mortality rate on human capital accumulation and 
population growth increases the transition path from 97 to 137 years by means of increasing the second and third stages' transition length, implying that the economy reached the steady state in 1897, 40 years later. This also sharply increases the proportion of output growth that is verified when economy is in transition: from $7.6 \%$ to $33 \%$.

Second, for all the simulations, the model replicates relatively small stages of capital accumulation. ${ }^{27}$ This means that our model fits historians' beliefs about the increasing role of R\&D in developing economies (see Maddison, 1995 and Crafts, 1995 and 1996). This is seen particularly in the benchmark case (the industrialized world), where first, second stage and total length are shorter than in the UK extension, due to better human capital institutions in the industrialized world that also lead to higher growth rate in the steady state. However, once the economy begins investing in $R \& D$, a fast approximation to the steady state takes place in the first years of the third stage. This is easily seen by observing growth rates in the last two columns of Table 4.2. These growth rates are consistent with the real ones, for the industrialized world between 1973 and 1992: 1.4\%. It is also from Table 4.2. that the most unrealistic model feature is shown: growth rates in the first stage are particularly high when compared to available data. This problem may come from two sources: (1) the selected value for final interest rate for simulation or (2) the period of the first stage in the model is shorter than the actual one. Our experiments have shown that changes of the assumed final interest rate do not affect final growth rates but only the period length. The second reason, however, may lead to a mismatch between the available figures and model predictions for the first period length, which are, in some simulations, slightly smaller when compared with historical descriptions. Real figures may include part of the second period in the model. As we show in the fourth line of Table 4.2., only an increase in the physical capital share in the first period could account for this, as is the case also in King and Rebelo (1993). As Table 4.1. (fourth line) shows, this, however, increases the length of the first stage. This approximates the growth rate of per capita GDP to that suggested by Crafts (1995) as an average for the period between 1760 and $1780(0.6 \%)$, although it continues to present quite a high value for growth in the beginning of the period.

Moreover, under a wide range for the parameter $\gamma$, we were able to replicate actual levels of GDP per capita (or average growth rates). The different values for this parameter depended on the underlying assumption for the other parameters, i.e., the existence of demographic transition, a different share of capital in the first stage or the existence of spillovers, for instance.

To sum up, it is advisable to think that the real value for $\gamma$ is between 0.5 and 1 in the set of industrialized countries considered. More important than this, is the conclusion according to which this parameter is not only important to repli-

\footnotetext{
${ }^{27}$ These lengths are in the range suggested by economic historians: from 20 to 50 years for the first stage and between 9 and 50 years for the second (see, for instance, Crafts (1995) and the WP version of this work). However, from the two first stages, only the second is "endogenous": simulation reports smaller values for the upper bound of the suggested interval for this stage.
} 
cate average growth rates during the last two centuries, but also has important effects in development differences today. This may contribute to easily explain the differences between development in the industrialized world (and particularly in the USA) and United Kingdom today, linking those differences to human capital institutions, as was also noted by economic historians (Crafts, 1995 and Mokyr, 1990 are just examples). Beginning with a difference in GDP per capita that favored the latter (of around 700 international dollars), a difference in the sensitivity of the human capital to the mortality rate of less than $30 \%$ (from 0.76 to 0.97 ) may account for the overcoming of the former set of countries. As we had interpreted this parameter as the quality of institutions that protect human capital accumulation, such as health and welfare services, education system, and civil or public order, these may have crucial importance in determining development differences today. As this effect has proven to be relevant in replicating paths of development and explaining differences of development, the next step is to compare the impact of this feature with an alternative and well-known explanation for different paths and levels of development: property-rights for ideas (varieties).

As the first stage remains with some contrafactual implications (as was recognized by King and Rebelo, 1993), for this propose we will use the Extension "Without First Stage" for the following analysis. ${ }^{28}$

\section{Comparing Mortality rate with Property Rights}

In this section we compare the relative importance of human capital protective institutions with $\mathrm{R} \& \mathrm{D}$ protective institutions. In particular, we compare the impact of variations in the sensitivity of human capital to the mortality rate and the impact of differences on property rights, both in consumption and in welfare. With this propose, we calculate an index of consumption two hundred years after the beginning (we normalized the initial value for consumption in the "Without First Stage" case to one and set the obtained final value to 100) and an index of utility. This last index is calculated as $U_{0}=\int_{0}^{\infty} \frac{c_{t}^{1-\theta}}{1-\theta} e^{-\left(\rho-b^{n}\right) \tau} d \tau$ (using the trapezoid rule). We do not impose any initial conditions, although we consider $K$ fixed across simulations. ${ }^{29}$ This exercise answers the question: how the industrialized world must have behaved if institutions in place in the economy were different; say the economy had better or worse protection to human capital or to R\&D. Table 6.1 shows results for the "Without First Stage" simulation (with $\gamma=0.56$ ), for worse human capital institutions (with $\gamma=$ 0.784 ), for erosion of monopoly power (MP) (with $p=0.5$, which means that the probability of a new variety still being monopolized in the next period is

\footnotetext{
${ }^{28}$ It can be shown that the use of the benchmark exercise does not affect the crucial result in the paper. However, we believe that beginning with the second stage improves the fit of our results to reality. Results for the benchmark exercise are shown in Appendix C - Table 1.C.

${ }^{29}$ Results do not change if $C$ is considered fixed across simulations. The normalization of initial consumption to one does not change our conclusions.
} 
about $60 \%$ ) and for the absence of property-rights law and enforcement - No PR (which implies that the third stage does not exist). Table 6.2 adds information about the importance of transitional dynamics in the model.

Table 6.1: Comparing the influence of Mortality Rate with Property Rights

\begin{tabular}{ccccccc}
\hline & \multicolumn{2}{c}{ Transition (Stages) } & $\gamma$ & $C$ & $U_{0}$ \\
& $2^{\text {nd }}$ & $3^{\text {rd }}$ & Total & & & \\
\hline W. First Stage & 23.6 & 91.3 & 114.9 & 0.56 & 100 & 100 \\
Worse HC-I. & 26.7 & 94.3 & 121.0 & 0.784 & 47.0 & 18.5 \\
Erosion MP & 21.3 & 91.9 & 113.2 & 0.56 & 87.6 & 95.7 \\
No PR & 368.8 & - & 368.8 & 0.56 & 45.8 & 7.3
\end{tabular}

Notes: Numbers are in years, with the exception of those in the columns for $\gamma, \mathrm{C}$ and $\mathrm{U}$.

Table 6.2: Proportion of transitional dynamics

\begin{tabular}{ccc}
\hline & $\begin{array}{c}\text { \% C } 1998 \\
\text { in transition }\end{array}$ & $\begin{array}{c}\text { \% Utility } \\
\text { in transition }\end{array}$ \\
\hline W. First Stage & 31.3 & 3.9 \\
Worse HC-I. & 43.3 & 16.0 \\
Erosion MP & 30.6 & 3.6 \\
No PR & 100.0 & 73.7 \\
\hline
\end{tabular}

Table 6.1 shows that both types of incentives (linked to human capital accumulation or linked to property rights) have dramatic effects on growth and development. More precisely, a difference of $40 \%$ (from $\gamma=0.56$ to $\gamma=0.784$ ) in the sensitivity of human capital accumulation to the death rate (or in the death rate, given the sensitivity) imply a greater than $1 / 2$ decrease in consumption per capita and utility. A higher parameter leads again to lengthier second-stages, where the economy is growing due to human and physical capital investment, to lengthier transition paths, lower welfare and also to a greater importance of transition dynamics in explaining actual consumption per capita and utility, as shown in Table 6.2. These last results suggest that the importance of transitional dynamics increases as institutions' quality decreases.

If the country had not set up a property rights system to protect new ideas, it could only grow due to human and physical capital accumulation. This would lead to a per capita consumption nearly $50 \%$ lower than otherwise. This means that these institutional differences can well account for huge welfare and consumption differences. It is worth noting that the absence of property rights leads to a lengthier transition and consequently, to its greater weight in explaining actual consumption and utility. ${ }^{30}$ However, the erosion of monopoly power, i.e., the probability of a good to lose the protective power of the patent shows a lower

\footnotetext{
${ }^{30}$ This seems to conclude that the "steady state need not be the full story about the growth of nations" (King and Rebelo, 1993: 914) and adds the evidence that the importance of transitional dynamics crucially depends on incentives (and institutions) being in place in the economy.
} 
influence in the final level of development and does not influence growth rates. This happens because in this model agents can re-allocate their human capital effort between three different uses: final good, education and research. When property rights are not secure (although an institutional patenting system set up does exist), people allocate more effort to other activities than research. For instance, in the "Without First Stage" economy (at the innovative stage steady state) the decentralized economy allocates $10 \%$ of human capital to research and development. When the insecurity in monopoly power is of $40 \%$, as it is in the third line of Table 6 , the economy only allocates $0.8 \%$ of human capital to research and it chooses a much higher steady-state knowledge-ideas ratio. This however does not affect growth rates, and the overall performance of the economy is slightly weaker than it was before.

The mortality rate and human capital protective institutions have a greater impact than that of property rights on final consumption per capita and welfare. Four results support this conclusion. First, there is not any number for $p<\infty$ that allows for the replication of the actual final value of GDP per capita, with a value of $\gamma=0$, this is, although the impact of the mortality rate in human capital accumulation is capable of replicating average performance of the industrialized world in the last two and a half centuries (see Table 4.1), the erosion of monopoly power is not! Second, the same percent variations in institutions' quality implies that differences in final consumption per capita and welfare are lower when the differences are obtained due to variations in $R \& D$ protective institutions than when they are obtained due to variations in human capital protective institutions (compare the first line with the last one and the second with the third lines in Table 7). Third, an increase in $\gamma$ of $75 \%$ (from 0.56 to 0.98 ) is equivalent to the absence of property rights in terms of welfare. Fourth, a value of $\gamma=1.35$ (an increase of $141 \%$ ) that avoids investment in human capital - this is what happened to R\&D investments in the "No PR" extension - would lead to no growth at all, and thus to a difference of $99 \%$ in consumption and $100 \%$ in utility.

We may wonder that the possible presence of spillovers in R\&D changes this result. However, as Table 7 indicates, the presence of spillovers does not dismiss our result.

In Table 7, we compare the same differences in R\&D protection (that is, a difference in the probability of a good to be monopolized at a given moment) $e^{-p}$ - and in the sensitivity of human capital to the mortality rate $-\gamma$. As these measures are in different units (the first is a probability and the second measure impact), we standardize the analysis using percentage differences. ${ }^{31}$

\footnotetext{
${ }^{31}$ However, even differences could be calculated in a different way: instead of using variations in $e^{-p}$ to measure percentage differences in $\mathrm{R} \& \mathrm{D}$ protective institutions, we could have used variations in $p$, instead. In fact, $e^{-p}$ and $\gamma$ have different intervals. Although the first is bounded in $100 \%$, the latter is not upper bounded. It is worth noting that using that variable, we are more demanding on the comparative mortality rate influence. In fact, a $40 \%$ variation in an initial value of $p$ leads to a smaller variation in $p$ than the same variation in $e^{-p}$, and an even smaller impact of R\&D was obtained.
} 
Table 7: Welfare losses due to Worst Property Rights and Higher Mortality

\begin{tabular}{ccccccc}
\hline & Parameter changes & \% difference & \multicolumn{4}{c}{ Spillovers } \\
\hline & & in quality & Without $(\phi=0)$ & With $(\phi=0.2)$ \\
& & of institutions & $C$ & $U$ & $C$ & $U$ \\
\hline No PR & $e^{-p}$ (from 1 to 0) & $100 \%$ & $54 \%$ & $93 \%$ & - & - \\
Erosion MP & $e^{-p}$ (from 1 to 0.6) & $40 \%$ & $12.4 \%$ & $4.3 \%$ & $14.8 \%$ & $4.2 \%$ \\
Worse HC-I 1 & $\gamma$ (from 0.56 to 0.784) & $40 \%$ & $53 \%$ & $82 \%$ & $54 \%$ & $95 \%$ \\
Worse HC-I 2 & $\gamma$ (from 0.56 to 0.98) & $75 \%$ & $76 \%$ & $93 \%$ & $77 \%$ & $98 \%$ \\
Worse HC-I 3 & $\gamma$ (from 0.56 to 1.12) & $100 \%$ & $86 \%$ & $97 \%$ & $87 \%$ & $99 \%$ \\
\hline
\end{tabular}

These experiments show that this environment attributes a much weaker role to intellectual property rights than Jones (2001) or Kortum (1997), for instance. However, the link between human capital and R\&D suggests that the human capital protective institutions are also protective for R\&D. If human capital protective institutions are so bad that human capital accumulation is not possible, $\mathrm{R} \& \mathrm{D}$ will not occur. Thus, $\mathrm{R} \& \mathrm{D}$ is also dependent on institutions linked to human capital. This can be seen in the "Worse HC Institutions" extension, where R\&D is delayed due to high sensitivity of human capital to the mortality rate.

The following figure (Figure 3 ) shows the evolution of per capita consumption index according to the differing protection given to human capital and R\&D presented in Table 7. It compares the "Without First Stage" extension with "Erosion MP", "Worse HC-I 1" and "No Property Rights". This is interesting because it clearly shows the greater influence of "Worse HC-I" extensions. It is also worth noting that decreasing Property Rights has a higher relative impact after some years, but lower impact earlier on. For instance, for the "No PR" case, consumption is higher in the first periods and after 200 years it may become worse than the worse human capital institutions case. This fact will have a crucial effect on utility, as this "Worse HC-I 1" $(\gamma=0.784)$ extension yields higher welfare than the "No Property Rights" extension. As Table 7 illustrated, a somewhat higher effect of mortality $(\gamma=0.98)$ - which we did not depict in the figure for reasons of clarity - is needed to equalize the welfare effect of this extension. 


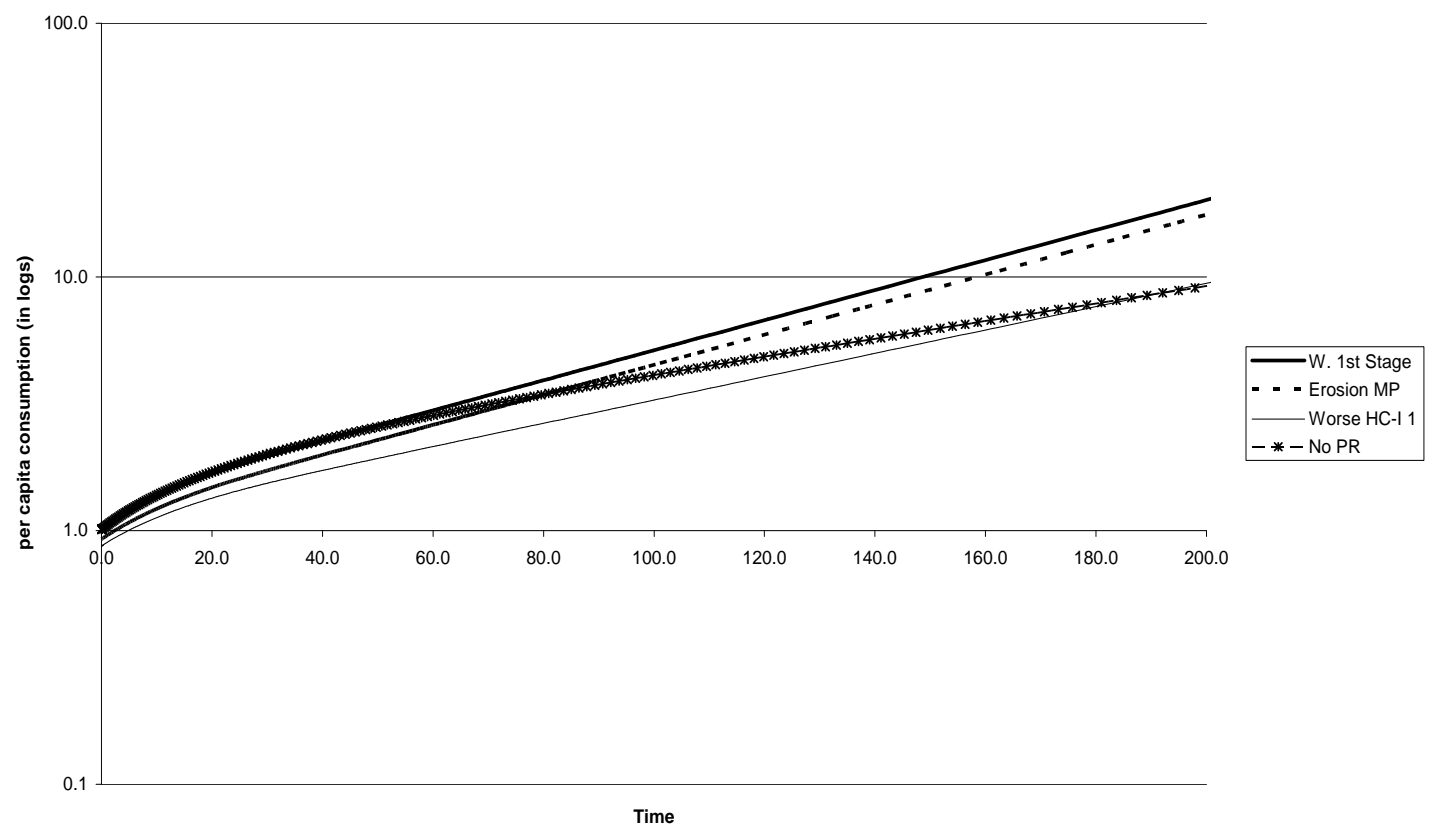

Figure 3. Evolution of per capita Consumption in two-stage economies with different institution qualities

\section{$7 \quad$ An institutions-improving State}

Is the State important to build and enforce institutions that affect growth and development? A number of studies have explored the empirical connection between measures of political stability and bureaucratic competence, on the one hand, and rates of economic growth, on the other. ${ }^{32}$ There is some evidence that a stable and competent state is indeed a contributing factor in economic growth. Recently, Bockstette et al. (2002) discovered that state antiquity contributes significantly to differences in growth rates and is also a good instrument for "social infrastructure". ${ }^{33}$ However, questions like: "how much tax should be supported to held appropriate institutions for growth?" and consequently "how important is a tax collector and institutions-builder and enforcing government to economic growth theory?" are questions without answers until now. Our

\footnotetext{
${ }^{32}$ See, for instance, Alesina et al. (1996) and Mauro (1995)

${ }^{33}$ In England, for instance, during the industrial revolution, taxes went up sixteen times between 1688 and 1815, particularly in war times. However, it can be argued that most of the money seems well spent because between 1688 and 1815 no invasions of the homeland took place, and also foreign aggression to British commerce and territories overseas declined in significance. Although persons and property were not effectively protected against crime and violence, the Hanoverian authorities certainly became more prepared to repress all challenges to good order and social stability during the eighteenth century (O'Brien, 1994).
} 
model is appropriate to answer these questions. On the one hand, it encompasses the most important economic growth models in a coherent endogenous setting (due to Funke and Strulik (2000)) and on the other, its results show a crucial importance of different types of institutions to the development of the world.

In this section we will assume the existence of a Government which enforces institutions (education, health, sanitation and property rights), through a tax rate on asset income. ${ }^{34}$ As in Peretto (2003), the most effective tax is the one on the asset income $(\mathrm{ra})$. However, due to the fact that it is the productivity of human capital accumulation that determines growth, no usual tax has effects on the steady-state growth rates (as in Arnold, 1998). In the transition, our experiments showed that the tax on asset income is quantitatively more important than that on the human capital income $\left(w\left(H-H_{H}\right)\right)$. Because of that and for simplicity of calculations, we use only the first tax. This tax introduced at time 0 will decrease the net interest rate at this period, keeping the stock of physical capital unchangeable but allowing for instantaneous "jumps" in consumption. ${ }^{35}$

We calculate the amount the representative agent is willing to pay for the enforcement of high-quality institutions. The assumption in doing this is that the tax returns are spent on keeping the quality of institutions (maintaining quality of schools, justice and health) and that otherwise quality will decrease by some given amount. ${ }^{36}$ We show results for maintaining quality of institutions when compared with a fall of $30 \%, 40 \%$ and $100 \%$ in their quality. ${ }^{37}$

Table 8: Increase in the Quality of Institutions Equivalent to given tax rates

\begin{tabular}{ccc}
\hline $\begin{array}{c}\text { Increase } \\
\text { in Education/Health Quality }\end{array}$ & $\begin{array}{c}\text { Ad-Valoren Tax on Wealth } \\
\text { for HC Institutions }\end{array}$ & $\begin{array}{c}\text { Ad-Valoren Tax on Wealth } \\
\text { for R\&D Institutions }\end{array}$ \\
\hline$\%$ & $\gamma^{*}$ & $p^{* *}$ \\
\hline $30 \%$ & $52.2 \%$ & $1.0 \%$ \\
$40 \%$ & $71.8 \%$ & $1.2 \%$ \\
$100 \%$ & $80.0 \%$ & $79.7 \%$ \\
\hline
\end{tabular}

Notes: ${ }^{*} 30 \%$ and $40 \%$ are equivalent to a change from $\gamma=0.56$ to $\gamma=0.728$ and to $\gamma=0.784$, respectively.

** $30 \%$ and $40 \%$ are equivalent to a change from $p=0$ to $p=0.36$ and to $p=0.50$, respectively.

It becomes clear that agents are willing to pay high taxes over wealth in order to maintain institutions at high levels. ${ }^{38}$ More important than this is

\footnotetext{
${ }^{34}$ By assumption, Government keeps a balanced budget each period. Taxes are only spent on enforcing institutions. The model is developed in Appendix A.

${ }^{35}$ To account for that, we fixed the $r_{0}$ at $6.5 \%$.

${ }^{36}$ A lump-sum tax gives trivial results, because it has no growth effects.

${ }^{37}$ With high tax rates, the economy does not have transitional dynamics. These taxes are calculated at the steady state.

${ }^{38}$ These high values for tax rates are due to low influence of taxation in this model, as Arnold (1998) pointed out.
} 
the fact that agents are willing to pay higher taxes to enforce human capital protective institutions than to enforce R\&D institutions. This confirms our previous conclusions on the greater impact of human capital (HC) institutions - linked with the impact of mortality - than that of R\&D institutions - linked with the protection of new ideas.

\section{Conclusions}

We show that the influence of mortality rate on human capital accumulation, recently established in the economic literature (e.g. Zhang et al. (2001), Zhang et al. (2003), and Kalemli-Ozcan et al. (2000)), is very important for a set of established growth models to encompass recent economic history. This can easily replicate the final difference in per capita income between countries.

We add to the economic literature linked with the industrial revolution (e.g. Goodfriend and McDermott (1995), McDermott (2002), Lucas (1993), Jones (2001), Gollin et al. (2002) and Hansen and Prescott (2002)) the particular interest with the "second-type" industrial revolution, linked with the transition to an R\&D-intensive stage. Once the economy has begun to invest in human capital, it will, at some point in time, experience a second type industrial revolution. We have drawn the economic path of the economy for the last 250 years using the most well-known models of economic growth. We have concluded that the $R \& D$ last stage is the lengthiest one and that the transition is important in explaining GDP, consumption and welfare. Its importance is crucially dependent on institutions in the economy. This enriches the usual characterization of "modern times" as "Solow" times (as in Hansen and Prescott (2002)).

The main contribution of the paper, which adds to recent theoretical treatment of incentives and property-rights (North (1994), Jones (2001), Kortum (1997), Lindner and Strulik (2004) and some of the cited above), is the comparison between the influence of the mortality rate and property rights, respectively linked with "expropriation" of human capital and patents, on growth and development. Contrary to most previous work, we conclude that, quantitatively, the sensitivity of human capital to the mortality rate and the mortality rate itself (which can be identified with public provision of education, health, sanitation, medication and so on) has a more dramatic influence on development than do property rights. Moreover, we argue for the potential important role of Governments as institution builders. This is shown because agents are willing to pay high tax rates to maintain high-level institutions.

Future research may proceed in three different and potentially fruitful directions. First, it should pay attention to the important institutions that enhance human capital accumulation in different sets of countries, which can also be viewed as institutions necessary to $R \& D$. Second, it may study mechanisms that could increase the influence of erosion of monopoly power in the economy, such as adaptation costs (or contracts) between sectors, for instance. Finally, it may develop more focused settings to analyze the role of Government in building and improving institutions. 


\section{References}

[1] Acemoglu, D. and F. Zilliboty (2001), Productivity Differences, Quarterly Journal of Economics, May, 116(2), 563-606.

[2] Alesina, A. and R. Perotti (1996), "Income Distribution, Political Instability and Investment", European Economic Review, 40(6), 1203-1228.

[3] Arnold, L. (1998), "Growth, Welfare and Trade in an Integrated Model of Human-Capital Accumulation and Research", Journal of Macroeconomics, 20(1), 81-105.

[4] Barrio-Castro, T., López-Bazo, E. and Serrano-Domingo, G. (2002), "New Evidence on International R\&D spillovers, human capital and productivity in the OECD", Economics Letters, 77, 41-45.

[5] Bloom, D., D. Canning and J. Sevilla (2001), The Effect of Health on Economic Growth: Theory and Evidence, NBER working Paper 8587.

[6] Bocksette, V., A. Chanda and L. Putterman (2002), "States and Markets: The Advantage of an Early Start", Journal of Economic Growth, 7:347-369, May.

[7] Brunner, M. and H Strulik (2002), "Solution of Perfect Foresight Saddlepoint Problems: A simple methods and Aplications, Journal of Economics Dynamics and Control, 25(5):737-753, May.

[8] Costa, D. and Steckel, R. (1995), Long-term Trends in Health, Welfare and Economic Growth in the United States, NBER Historical Paper 76.

[9] Crafts, N. (1995), "Exogenous or Endogenous Growth? The Industrial Revolution Reconsidered", Journal of Economic History, v.55, n.4, December, 745-772.

[10] Cropper, M. L. (2000), "Has economic research answered the needs of environmental policy?", Journal of Environmental Economics and Management, 328-350.

[11] Funke, M. and H. Strulik (2000), "On Endogenous growth with physical capital, human capital and product variety", European Economic Review, 44, 491-515.

[12] Goodfriend, M. and J. McDermott (1995), "Early Development", American Economic Review, v. 85, March, 116-133.

[13] Gollin, D. et al. (2002), "The role of Agriculture", American Economic Review, 92(2), May, 160-164.

[14] Grossman, G. and Helpman, E. (1991), Innovation and Growth in the global economy, MIT press. 
[15] Haines, M. (2001), The Urban Mortality Transition in the United States, 1800-1940, NBER Working Paper 134.

[16] Hansen, G. and E. Prescott (2002), "Mathus to Solow", American Economic Review, 92(4), September, 1205-1217.

[17] Jones, C. (1995), "R\&D-based models of endogenous growth", Journal of political Economy, vol. 103, n.4, 759-584.

[18] Jones, C. (2001), "Was an Industrial Revolution Inevitable? Economic Growth over the very Long Run", Advances in Macroeconomics, The B.E. Jounals in Macroeconomics, The Berkeley Electronic Press.

[19] Jorgenson, D. and B. Fraumeni (1993), "Education and Productivity Growth in a Market Economy", Atlantic Economic Journal, vol. 21, issue 2, June, 1-25.

[20] Kortum, S. (1997), "Research, Patenting and Technological Change", Econometrica, vol. 65, issue 6, November, 1389-1419.

[21] Lindert, P. (1994), "Unequal Living Standards" in Fould and McCloskeys (eds.), The Economy of Britain since 1700, Volume 1:1700-1860, Second Edition, Cambridge University Press.

[22] Lindner, I. and H. Strulik (2004), Property Rights and Growth, Department of Economics, University of Hamburg, mimeo.

[23] Livi-Bacci, M. (1997), A Consice History of World Population, Backwell Publishers.

[24] Lucas, R. (1988), "On the Mechanics of Economic Development", Journal of Monetary Economics, 22, 3-42.

[25] Lucas, R. (1993), "Making a Miracle", Econometrica, 61(2), March, 251-72.

[26] Kalemli-Ozcan, S., H. Ryder and D. Weil (2000), "Mortality Decline, Human Capital Investment and Economic Growth", Journal of Development Economics, 62 (1), 1-23.

[27] Kalemli-Ozcan, S. (2002), "Does the Mortality Decline promote Economic Growth?", Journal of Economic Growth, 7, 411-439.

[28] King, R. and Rebelo, S. (1993), "Transitional Dynamics and Economic Growth in the Neoclassical Model", American Economic Review, 83(4), September, 908-931.

[29] Kremer, M. (1993), "Population Growth and Technological Change: One Million B.C. to 1990", Quarterly Journal of Economics, August, 681-716.

[30] Maddison, A. (1995), Monitoring the World Economy 1820-1992, Development Center Studies, OECD, Paris. 
[31] Maddison, A. (2001), The World Economy, a millenial perspective, Development Center Studies, OECD, Paris.

[32] Mauro, P. (1995), "Corruption and Growth", Quarterly Journal of Economics, 3(110), 681-712.

[33] McDermott, J. (2002), "Development Dynamics: Economic Integration and the Demographic Transition", Journal of Economic Growth, 7, 371-409.

[34] Meltzer, D. (1992), Mortality Decline, the Demographic Transition and Economic Growth, PhD Dissertation, University of Chicago.

[35] Mokyr, R. (1990), The Lever of Riches; Oxford, Oxford University Press.

[36] North, D. (1994), "Economic Performance through Time", American Economic Review, v.84, n.3, June, 359-368.

[37] O'Brien, P. (1994), "Central Government and the economy 1688-1815" in Fould and McCloskeys (eds.), The Economy of Britain since 1700, Volume 1:1700-1860, Second Edition, Cambridge University Press.

[38] Peretto, P. (2003), "Fiscal Policy and Long-Run Growth in R\&D-based Models with Endogenous Market Structure", Journal of Economic Growth, 8, 325-347.

[39] Preston, S. H. (1980), "Causes and Consequences of mortality declines in less developed countries during the twentieth century", in Easterlin, R. (Ed.), Population and Economic Change in Developing Countries, Chicago.

[40] S $\phi$ rensen, A. (1999), "R\&D, Learning and Phases of Economic Growth", Journal of Economic Growth, 4, 429-445, December.

[41] Uzawa, H. (1965), "Optimal Technical Change in an Aggregative Model of Economic Growth", International Economic Review 6, 18-31.

[42] Zhang, J. et al. (2003), "Rising Longevity, education, savings and growth", Journal of Development Economics, v.70, 83-101.

[43] Zhang, J. et al. (2001), "Mortality Decline and Long-Run Economic Growth", Journal of Public Economics, v.80(3), 485-507.

\section{Appendix}

\section{A Model with Government}

Government uses taxes on physical capital and human capital income to enforce institutions and keeps a balanced budget from period to period. Thus the 
Government spends tax income on building institutions. The physical capital tax changes equation (10) to include a smaller private net return on capital,

$$
r=\left(1-\tau_{k}\right) \frac{\beta Y}{K},
$$

where $\tau_{k}$ is a tax on physical capital which first affects $g_{K}$. We can re-write (18) as

$$
\dot{K}=(1-\alpha \eta) Y-C-\tau_{k} \frac{\beta Y}{K} K
$$

Naturally, all equations in the model previously affected by (18) will now be affected by (41). In particular, using (40) and (41), equations that characterize the first stage (25) and (26), can be restated as:

$$
g_{r}=-\frac{1-\beta-\eta}{1-\eta}\left(\frac{1}{\left(1-\tau_{k}\right)}\left(\frac{1-\alpha \eta}{\beta}-\tau_{k}\right) r-C / K\right)
$$

and

$$
g_{C / K}=\left(1 / \theta-\frac{1}{\left(1-\tau_{k}\right)}\left(\frac{1-\alpha \eta}{\beta}-\tau_{k}\right)\right) r+C / K-\rho / \theta+b^{n} .
$$

It is well-known in the literature that this type of tax has a level effect in a Ramsey-type model, decreasing the value of the equilibrium physical capital. In the period that the tax is introduced, net interest rate decreases by the value of $\left(1-\tau_{k}\right)$.

\section{B Model with Spillovers}

We have considered an R\&D function used in Jones (1995) $\dot{n}=\epsilon H_{n} n^{\phi}$, which implies that the free-entry condition in R\&D will be written as $v n^{\phi}=\frac{w}{\epsilon}$.

The following expressions substitute expressions in the third stage of development:

$$
u_{1}=\frac{\xi-\gamma d+\phi g_{n}+p}{\epsilon} \frac{(1-\beta-\eta)}{(1-\alpha) \eta} \frac{n^{1-\phi}}{H}
$$

This implies that $g_{u_{1}}=(1-\phi) g_{n}-g_{H}$. From this equation and eq.(21) the growth rate of innovations can be written as $g_{n}=\frac{g_{Y}-g_{w}}{1-\phi}$. Insertion of eqs.(20) and the last two into eq.(19) provides growth rate of the interest rate according to:

$$
\begin{aligned}
\left(1-\frac{1-\alpha}{\alpha} \frac{\eta}{\beta} \frac{1}{1-\phi}\right) g_{r} & =-\left[\frac{1-\alpha}{\alpha} \frac{\eta}{\beta} \frac{1}{1-\phi}+\frac{(1-\beta-\eta)}{\beta}\right] g_{w}+ \\
& +\frac{1-\alpha}{\alpha} \frac{\eta}{\beta} \frac{1}{1-\phi} g_{K}
\end{aligned}
$$


After substituting $g_{w}$ and $g_{K}$ from equations (24) and (28), the last equation can be re-written as,

$$
\begin{aligned}
\left(1-\frac{1-\alpha}{\alpha} \frac{\eta}{\beta} \frac{1}{1-\phi}\right) g_{r} & =\left\{\frac{1-\alpha}{\alpha} \frac{\eta}{\beta} \frac{1}{1-\phi}[(1-\alpha \eta) / \beta-1]-\frac{(1-\beta-\eta)}{\beta}\right\} r- \\
& -\frac{1-\alpha}{\alpha} \frac{\eta}{\beta} \frac{1}{1-\phi} C / K+\left[\frac{1-\alpha}{\alpha} \frac{\eta}{\beta} \frac{1}{1-\phi}+\frac{(1-\beta-\eta)}{\beta}\right](\xi-\gamma d)
\end{aligned}
$$

To reveal the dynamics of the knowledge formation, we define the knowledgeideas ratio as $H / n^{1-\phi}$ and obtain from equations (2), (1) and (32)

$$
g_{H / n}=(\xi-\gamma d)\left[1-\left(\left(\xi+\phi g_{n}+p-\gamma d\right) A_{2} / \alpha+g_{n}\right) / H / n \epsilon\right]-g_{n}(1-\phi)
$$

The dynamics of the model can be characterized by (26), (46) and (47). Therefore, we can characterize steady state as

$$
\begin{gathered}
r^{*}=\frac{\theta(\xi-\gamma d)\left(1+A_{2}\right)-\rho+\theta b^{n}}{(\theta-1)+\theta A_{2}} \\
C / K^{*}=\rho / \theta+\left(\frac{1-\alpha \eta}{\beta}-1 / \theta\right) r_{s}-b^{n}
\end{gathered}
$$

which implies that

$$
g_{n}^{*}=\frac{(\xi-\gamma d-\rho) A_{2}+\theta A_{2} b^{n}}{\left((\theta-1)+\theta A_{2}\right)(1-\phi)}
$$

and

$$
H / n^{*}=\frac{(\xi-\gamma d)}{\epsilon} \frac{(1-\beta-\eta)\left(\xi+\phi g_{n}+p-\gamma d\right) /[(1-\alpha) \eta]+g_{n}^{*}}{\xi-\gamma d-(1-\phi) g n^{*}}
$$

where $A_{2}=\frac{\alpha(1-\beta-\eta)}{(1-\alpha) \eta}(1-\phi)$.

\section{Comparing Mortality Rate with Property Rights - Benchmark}

Table 1.C: Welfare losses due to Worst Property Rights and Higher Mortality

\begin{tabular}{ccccccc}
\hline & Parameter changes & \% decrease & \multicolumn{4}{c}{ Spillovers } \\
\hline & & in quality & \multicolumn{2}{c}{ Without $(\phi=0)$} & With $(\phi=0.2)$ \\
& & of institutions & $C$ & $U$ & $C$ & $U$ \\
\hline No PR & $e^{-p}$ (from 1 to 0) & $100 \%$ & $54.0 \%$ & $73.6 \%$ & - & - \\
Worst PR & $e^{-p}$ (from 1 to 0.6) & $40 \%$ & $15.1 \%$ & $4.4 \%$ & $27.4 \%$ & $4.8 \%$ \\
Higher Mort. & $\gamma$ (from 0.76 to 1.064) & $40 \%$ & $70.7 \%$ & $68.6 \%$ & $73.5 \%$ & $74.0 \%$ \\
Higher Mort. & $\gamma$ (from 0.76 to 1.11) & $46 \%$ & $75.8 \%$ & $73.6 \%$ & $77.3 \%$ & $78.1 \%$ \\
\hline
\end{tabular}

